\title{
Article \\ Optimizing a Sustainable Supply Chain Inventory Model for Controllable Deterioration and Emission Rates in a Greenhouse Farm
}

\author{
Umakanta Mishra $^{1,2}\left(\mathbb{D}\right.$, Abu Hashan Md Mashud ${ }^{3} \mathbb{D}$, Ming-Lang Tseng ${ }^{4,5,6}{ }^{(D)}$ and Jei-Zheng Wu M $^{1, *(D)}$ \\ 1 Department of Business Administration, Soochow University, 56 Section 1, Kuei-Yang Street, \\ Taipei 10048, Taiwan; umakanta.math@gmail.com \\ 2 Department of Mathematics, School of Advanced Sciences, Vellore Institute of Technology, \\ Vellore 632014, India \\ 3 Department of Mathematics, Hajee Mohammad Danesh Science and Technology University, \\ Dinajpur 5200, Bangladesh; mashud@hstu.ac.bd \\ 4 Institute of Innovation and Circular Economy, Asia University, Taichung City 41354, Taiwan; \\ tsengminglang@gmail.com \\ 5 Department of Medical Research, China Medical University Hospital, China Medical University, \\ Taichung City 40402, Taiwan \\ 6 Faculty of Economic and Management, University Kebangsaan Malaysia, Bangi 43600, Malaysia \\ * Correspondence: jzwu@scu.edu.tw
}

Citation: Mishra, U.; Mashud, A.H.M.; Tseng, M.-L.; Wu, J.-Z. Optimizing a Sustainable Supply Chain Inventory Model for Controllable Deterioration and Emission Rates in a Greenhouse Farm. Mathematics 2021, 9, 495.

https://doi.org/10.3390/math9050495

Academic Editor: Armin Fügenschuh

Received: 9 February 2021

Accepted: 24 February 2021

Published: 28 February 2021

Publisher's Note: MDPI stays neutral with regard to jurisdictional claims in published maps and institutional affiliations.

Copyright: (c) 2021 by the authors. Licensee MDPI, Basel, Switzerland. This article is an open access article distributed under the terms and conditions of the Creative Commons Attribution (CC BY) license (https:// creativecommons.org/licenses/by/ $4.0 /)$.

\begin{abstract}
This study investigated how greenhouse managers should invest in preservation and green technologies and introduce trade credit to increase their profits. We propose a supply chain inventory model with controllable deterioration and emission rates under payment schemes for shortage and surplus, where demand depends on price and trade credit. Carbon emissions and deterioration are factors affecting global warming, and many greenhouse managers have focused on reducing carbon emissions. Carbon caps and tax-based incentives have been used in many greenhouses to achieve such reduction. Because of the importance of reducing carbon emissions for developing a green supply chain, various studies have investigated how firms deal with carbon emission constraints. In this continuation, we have used green technology to curb the excessive emissions from the environment or make it clean from $\mathrm{CO}_{2}$. In a seller-buyer relationship, the seller can offer a trade credit period to the buyer to manage stock and stimulate demand. Deterioration may become a challenge for most firms as they are under time constraints control, and preservation technology could help. This study proposes three novel inventory strategies for a sustainable supply chain (full backorder, partial backorder, and no backorder), linking all these important issues. The solution optimizes total annual profit for inventory shortage or surplus. We conducted a numerical study with three examples to evaluate the model's authenticity and effectiveness and demonstrate the solution technique. The deterioration and emission rates can be included in a trade credit policy to increase greenhouse profits. The results suggest that greenhouse managers could apply the proposed model to manage real-world situations.
\end{abstract}

Keywords: sustainable supply chain; inventory; controllable deterioration; carbon emission rate; carbon cap; carbon tax

\section{Introduction}

The sustainable supply chain is becoming an emerging concern in today's competitive business. A business is called sustainable when the three attributes: economy, environmental, and social parallel any business [1]. The present world focuses on environmental issues as the emissions of $\mathrm{CO}_{2}$ have increased significantly due to industrialization worldwide. To smoothly and efficiently run an industry, many different types of energy are required (e.g., electrical energy, solar energy, etc.). In Germany, electrical energy accounts for $47 \%$ 
of total energy consumption. In the United States, the manufacturing sector contributes approximately $33 \%$ of the total energy consumption and $28 \%$ greenhouse gas emissions. Established economies have substantial but declining carbon emissions; by contrast, the carbon emissions in emerging economies have rapidly increased. Asian countries, such as China, India, Japan, South Korea, Iran, Saudi Arabia, Indonesia, and Taiwan, are among the top $20 \mathrm{CO}_{2}$ emitters. Sustainable development is the optimal approach for emerging economy growth [2], and it mainly depends on proper environmental management. According to the Intergovernmental Panel on Climate Change, global warming caused by excessive carbon emissions has a massive impact on the environment [3]. Many developing countries have promoted emission conventions (e.g., cap and trade) to reduce emissions and have introduced high technology equipment [4] because increasing demand always results in a dynamic supply chain and maximum carbon dioxide emissions. When managing a dynamic supply chain, considering joint credit and replenishment policies is essential for dealing with decaying items with conservational disputes because environmental policies affect business decisions. Many researchers have discussed sustainable supply chain inventory (SSCI) models for product deterioration with credit policy strategies [5-7], but few studies have considered trade credit risk policy under environmental disputes. Deterioration and emissions are natural processes that reduce a product's effectiveness. In greenhouses, most products, such as vegetables and flowers, naturally deteriorate over time. To reduce carbon emissions, greenhouse managers can apply green technology investment. Therefore, inventory deterioration and environmental emissions should be reduced through investment in high-quality preservation technology (PRT) and green technology (GRT), respectively.

However, the conventional economic order quantity (EOQ) model undertakes minimum total cost for maximum profits. Demand among retailers requires determination of the credit period, and selling price determination requires thoughtful consideration of demand among retailers because the effect of the credit period on sales is minimal relative to that of unfulfilled demand [8]. A balance between the credit period and selling price yields additional profit. Johari et al. [9] developed an inventory model highlighting the real-world value of determining the credit period and selling price based on demand. The sensitivity of price to consumer demand causes the wholesale selling price to change with changes in demand. Therefore, pricing decisions and financing affect the demand rate and the inventory scheme. Implementing an optimal pricing policy yields profits for supply chain members and customers, with customers enjoying lower prices and supply chain members benefiting from higher demand. Johari et al. [9] revealed that these decisions have a downstream effect on the upstream chain members' profitability, with demand determined based on price.

Cheraghalipour and Farsad [10] studied a bi-objective supplier chain with two quantity discounts under the risk of disruption. They proved that disruption risks and quantity discounts are applicable in real-world situations. Furthermore, suppliers prefer extended credit periods because this can improve sales. Moreover, this increases retailers' capital and default risk rate, as proposed in [5]. Therefore, coordination is required to increase supply chain profitability.

In a conventional model, a retailer places an order, followed by the purchase cost payment. Sometimes, the supplier may require the buyer to reimburse them before the delivery date (known as advance payment), reducing the probability of order cancellation and enabling smooth goods management [11,12]. However, Lashgari et al. [13] indicated that the seller might offer a delayed payment to their buyers to stimulate sales. The present study investigated some common marketing policies, such as advanced and delayed payments to boost trade. Trade credit policy is widely considered a valuable technique for increasing sales or reducing on-hand inventory [14]. It inspires buyers to increase their orders by reducing their capital assets. The primary role of advanced payment is to increase sales and profits. Consumers are generally likely to reimburse the purchasing cost as advanced prepayments and attempt to achieve the supplier's accommodating profit 
when the interest earned differs from banks' interest rates. It is necessary to complete the supplier's process to obtain a portion of the purchasing cost in advance. This process ensures that the buyer places orders to the supplier.

Several researchers have developed SSCI models with attributes including backorders, preservation technology, green technology, delayed payments, and advanced payments. However, no studies have provided a model to explore the effects of PRT and GRT investment on deterioration and emissions rates when demand depends on trade credit and price with default risk under various backorder cases. This study is intended to formulate an SSCI model that considers preservation and carbon emission reductions under various shortage conditions. The main aims of this study are as follows:

(1) To investigate the simultaneous investment in PRT and GRT for credit-linked pricedependent demand;

(2) To reveal how retailers could invest in PRT and GRT to optimize deterioration and carbon emission rates;

(3) Explore the effects of backorder cases on the retail industry under various pricing strategies.

The remainder of this paper's organization is as follows: Section 2 reveals a research gap based on a review of the literature; Section 3 details the model formulation; Section 4 provides several numerical examples, explores the results, reports a sensitivity analysis, and lists managerial implications; and Section 5 concludes the study with some limitations and suggestions for future work.

\section{Literature Review and Methods}

In this section, a brief literature review on relevant studies has been provided at Section 2.1 and a case background has been provided at Section 2.2.

\subsection{Literature Review}

This study explores (1) an SSCI model with trade credit risk and (2) applying the SSCI model to environmental issues. The first part of this literature review discusses studies that assume price, trade credit, deterioration, demand, and default risk linked to particular credit period functions. The second part of the literature review introduces studies controlling deterioration and greenhouse emission rates.

Deterioration affects inventory management for spoilable products such as vegetables, fruits, greenhouse flowers, gasoline, and chemical products. Contemporary research has widely investigated this type of inventory model. Chen and Teng [8] presented the concept of deterioration through their model, in which the deterioration rate was constant. In this context, Bakker et al. [15] conducted a comprehensive review on deterioration from 1990 to 2011. In modern business, the retailer commonly uses trade credit to attract customers. Chen and Teng [8] introduced an inventory model in which the demand depends on the link between the selling price and credit. The general formula was better than the conventional EOQ inventory model in which demand depends on stock. Continuous resupply for deteriorating items applies to a firm's net present value for its future cash flow [16].

Sustainability is a crucial policy for economic growth. Ghosh et al. [17] developed a lotsizing model for stochastic demand under a strict carbon-cap policy. They determined the optimal order quantity by observing the effects of carbon trading, carbon prices, and carbon caps on total inventory costs, carbon emissions, and related decisions. Emission rates are controllable by using special equipment. The present study examined greenhouse farms in which the operation of some equipment results in high emissions. Greenhouse firms can use technology investment to reduce emission rates. Several studies have reported that emission rates are controllable by using inventory policies [4,17].

Growing the economy to boost customer demand is a challenging task for retailers and suppliers. Zhang et al. [18] developed an EOQ model with an advanced payment system, and Taleizadeh [19] provided a model that considers multiple prepayments and 
constant deterioration. Subsequently, Zia and Taleizadeh [20] attempted to combine partial prepayment with delayed payment based on inventory order quantity. Tavakoli and Taleizadeh [21] studied an inventory policy with a full prepayment scheme for deteriorating items, and Teng et al. [11] considered an inventory model with prepayment and planned backorders. Lashgari et al. [13] modified the concept of full prepayment and studied partial upstream advanced prepayments with trade credit for a three-level supply chain. Shah et al. [22] modified the model developed by Teng et al. [11] by applying a fixed rate of deterioration or no deterioration. Taleizadeh et al. [23] introduced a model for backorder prediction under an advanced payment scheme.

Notably, although trade credit policies increase sales, an extended credit period increases the default risk. Therefore, Dye and Yang [5] studied an inventory policy with default risk in the case of partial backlogging. Roghanian and Cheraghalipour [24] developed a metaheuristic to solve a multi-objective model in a closed-loop supply chain by assuming emission levels to maximize demand reactivity and minimize total costs and carbon emissions. Taleizadeh et al. [25] developed a pricing decision model for planned discounts and partial backorders to maximize profit without additional investments. In a sustainable production model, Taleizadeh et al. [26] considered emission costs and shortages to maximize profit without additional investments.

Moreover, Tiwari et al. [27] identified the optimal sustainable approach given credit policy and shortages of all items while minimizing total cost. After that, Tiwari et al. [28] and Mashud et al. [29] established a sustainable inventory system with imperfect item quality and deterioration, which minimized the carbon emission costs and total inventory costs. Based on emissions trading, Kumar and Uthayakumar [30] formulated a vendormanaged inventory decision model with unequal and equal shipments with an objective function maximized for various carbon cap trade policies. Ebrahimi [31] developed a stochastic multi-objective allocation-location-routing model to improve sustainability with quantity discounts. Wang et al. [32] studied pricing models for a sustainable supply chain with constraint capacity for deriving the recycling, pricing, and remanufacturing schemes. Wang et al. [33] introduced a sustainable supply chain management and inventory model without emission control that minimized costs, including environmental emissions costs. Gharaei et al. [34] investigated a multi-buyer supply chain, multi-product, green product, and quality control policies for a vendor's inventory problem with a shipment stock contract. They derived an outer estimate design with relaxation equality and a penalty algorithm. Recently, Mishra et al. [12] investigated a sustainable inventory problem with controlled deterioration and environmental emission rates, but they did not include various backorder conditions.

Researchers have assumed constant deterioration or a variable deterioration rate that is controllable by using special equipment. Kumar et al. [35] analyzed a production system with a trade credit policy, preservation technology, and an emissions regulation policy. They incorporated trade credit, but they did not assume that credit was linked to demand with default risk. By contrast, Mohanty et al. [36] investigated trade credit policies for a deteriorating product system with preservation technology, but they did not consider an emissions regulation policy. Several recent articles on supply chain management have explored the adoption of technology to reduce the deterioration rate. Zilberman et al. [37] investigated the effect of market power on supply chain efficiency. Du et al. [38] explored how risk influences the supply chain design, and Lu et al. [39] discussed reducing the adoption threshold in a rental market. The present study contributes to the literature by investigating greenhouse managers' decisions regarding PRT and GRT investment in a trade credit system. Mashud et al. [40] presented a model for deteriorating items in the newsboy problem with delivery strategy. Baek et al. [41] anticipated a model considering carbon emissions with a discount policy. They investigated an order allocation problem for a large-scale supplier selection process. Sett et al. [42] developed an inventory model with price, quality of products, and service-dependent demand for the O2O model. Vishkaei et al. [43] developed a retailer inventory system where the inspection system's reliabil- 
ity affects the percentage of defective items delivered to final customers. Esmaeili and Nasrabadi [44] studied an inventory model for the single-vendor multi-retailer supply chain under inflationary conditions and trade credit policy. Taghizadeh-Yazdi et al. [45] studied an integrated inventory system for multi-echelon supply chains with deteriorating items under a price-dependent demand approach. This study proposes a supply chain inventory model with controllable deterioration and emissions rates under payment schemes for shortage or surplus where demand depends on price and trade credit policy.

\subsection{Case Background}

This study's assumptions are implementable in various realistic scenarios. For example, in the greenhouse flower industry, stock levels of flowers should be sufficient to satisfy demand (Figure 1) [46]. Greenhouse flowers are not available everywhere, and their demand depends on trade credit, price, and default risk. Therefore, consumers pay attention to the minimum price when considering whether to buy more flowers. Greenhouse managers should use an inventory management system to control deterioration and emissions. Some greenhouse flowers are not available in summertime. Therefore, greenhouse managers can use PRT to lower the greenhouse temperature and thus reduce emissions and deterioration. Deterioration and emissions reduce the expediency and efficacy of a product relative to its initial state. Decreasing the rates of deterioration and emission by investing in PRT and GRT is vital. Such high-quality equipment can be purchased based on consumer prepayments and trade-credit-linked price-dependent demand. Therefore, in conducting this study, we were mindful that controllable deterioration and emission rates are not generally considered concerning consumer prepayments and trade-credit-linked price-dependent demand with default risk under various shortage issues.

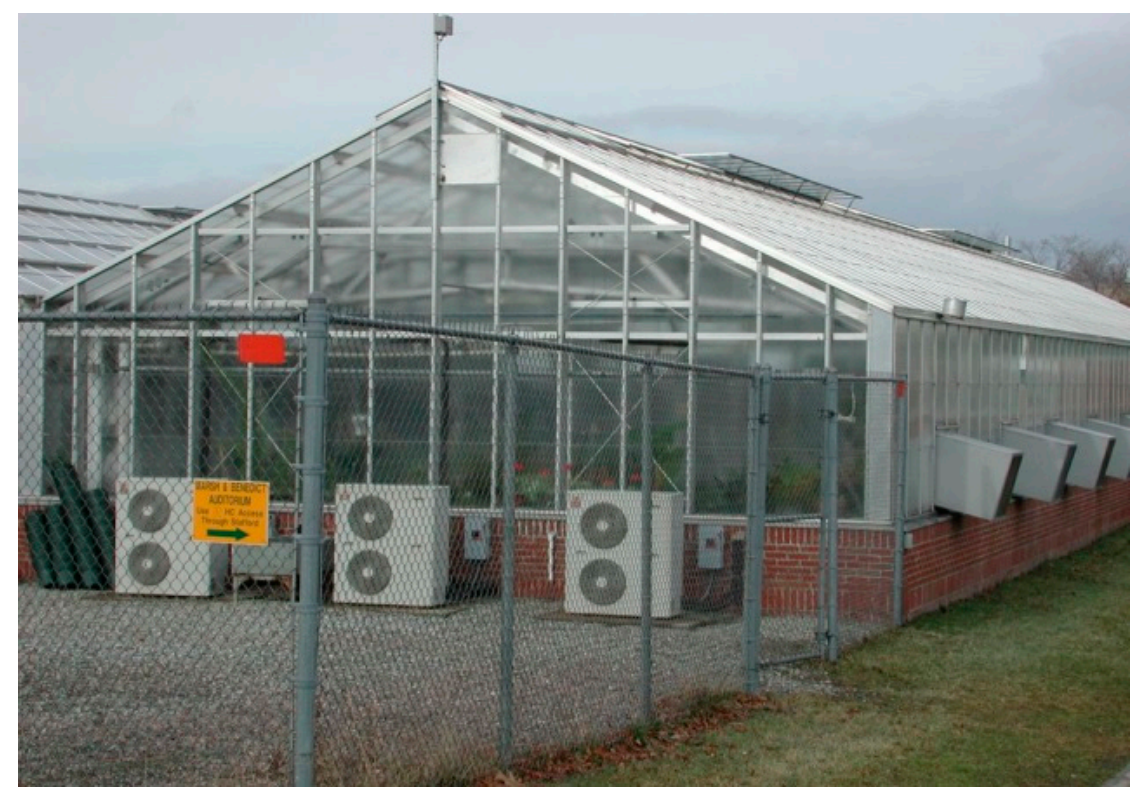

Figure 1. Greenhouse (flower farm) deterioration and emission control system (https:/ / slideplayer. com/slide/4765288/ (accessed on 27 February 2021)).

\section{Model Formulation}

This study developed an SSCI model for a supplier, a retailer, and customers under controlled item deterioration and carbon emission rates (Appendix A lists the notations used for formulating the inventory models). The supplier offers a prepayment policy to the retailer. Thus, the retailer pays a percentage of the supplier's acquisition cost when placing the order and pays the remainder through multiple equally spaced installments within the permitted lead time. This strategy helps the retailer to increase capital costs because of the interest accrued on these items. Moreover, customers pay retailers a percentage of 
the purchase cost within a specific time (the trade-credit period), which is shorter than the lead time of the supplier's advanced payments; the retailer adopts this strategy to attract customers.

The study scenario is particularly relevant to situations where a supplier requests that a retailer provide advanced sales payment depending on the selling price. The retailer must prepay some portion of the purchasing cost, and the payment is complete through multiple installments. In this situation, the retailer may obtain a loan from a financial institution, such as a bank, to make advanced payments. Then, the retailer repays the loan using revenue from product sales. We considered three types of SSCI to investigate capital investments' consequences for reducing product deterioration and environmental emissions. Retailers should begin to repay their loans when obtaining revenue from customers. The proposed model comprises the following three conditions: (1) partial backorders, (2) full backorders, and (3) no backorders. This study aims to formulate an SSCI model with controlled deterioration and carbon emission rates and determine capital investments' productivity.

The proposed SSCI model comprises the following two circumstances: (i) with shortages (i.e., partial and full backorders) and (ii) without shortages. The following assumptions are adopted:

1. The model includes a single deteriorating product.

2. The upstream side of the supply chain includes trade credit.

3. The downstream side of the supply chain includes a prepayment scheme.

4. Prepayments are equally sized.

5. The shortage is permitted.

6. The horizon is finite.

7. Product shortage includes partial and full backorders.

8. Demand $D(p, M)=(a-b p) e^{\zeta M}$ is a function of trade credit and selling price, where $p$ is selling price, $M$ is the trade credit period, $a$ is the demand scale, $b$ represents price sensitivity, $p<\frac{a}{b}, 0 \leq \zeta<1$, and $a>0, b>0[9,47]$.

9. The default risk rate for the credit period is $F(M)=1-e^{-\phi M}[5,48]$.

10. The retailer's opportunity cost for a trade credit period is $e^{-r M}$, where $r$ denotes the interest of the opportunity cost $(r>0)$ [3,42].

11. Deteriorated items have no value.

12. Deterioration rates are controllable through PRT investment [49].

13. The deterioration rate $\lambda(P)=\lambda_{0} e^{-u P}$ is a concave and continuous function of the retailer's total capital investment [46].

14. The cost of carbon emissions includes three components: replenishment, storage, and environmental impact. The detailed derivation is provided in Section 3.

15. A portion of the decrease of normal emissions is given by $F=\theta\left(1-e^{-m G}\right) ; \theta, m$, and $G$ are defined in Appendix A. $F=\theta\left(1-e^{-m G}\right)$. $F^{\prime \prime}(G)$ represents the reduction in the marginal capital $F=\theta\left(1-e^{-m G}\right) \Rightarrow G=-(1 / m)[\ln (1-F / \theta)]$.

In Sections 3.1-3.3, we interpret the distinct SSCI models.

\subsection{SSCI Model with Partial Backorders}

During product shortages, customers may not wish to pay for backorders and wait to obtain the product at the following replenishment point. For example, a customer may visit a greenhouse to purchase flowers or plants during a product shortage. If the customer is willing to place a backorder, the greenhouse manager can inform the customer of the replenishment date, as assumed in the existing EOQ model with partial backorders. In the model developed by Mishra et al. [10] and Taleizadeh et al. [25], the retailer prepays the supplier $k c Q$ in advance of the delivery time through $R$ equivalent installments during $L$ years (Figure 2). The retailer pays the remaining balance $(1-k) c Q$ after receiving the $Q$ ordered units. The stock level reaches zero at time $T$ in arrears to both demand $D(p, M)$ and deterioration rate $\lambda(P)$. In this model, shortages and full backorders are accrued during the period $[\alpha T, T]$. 


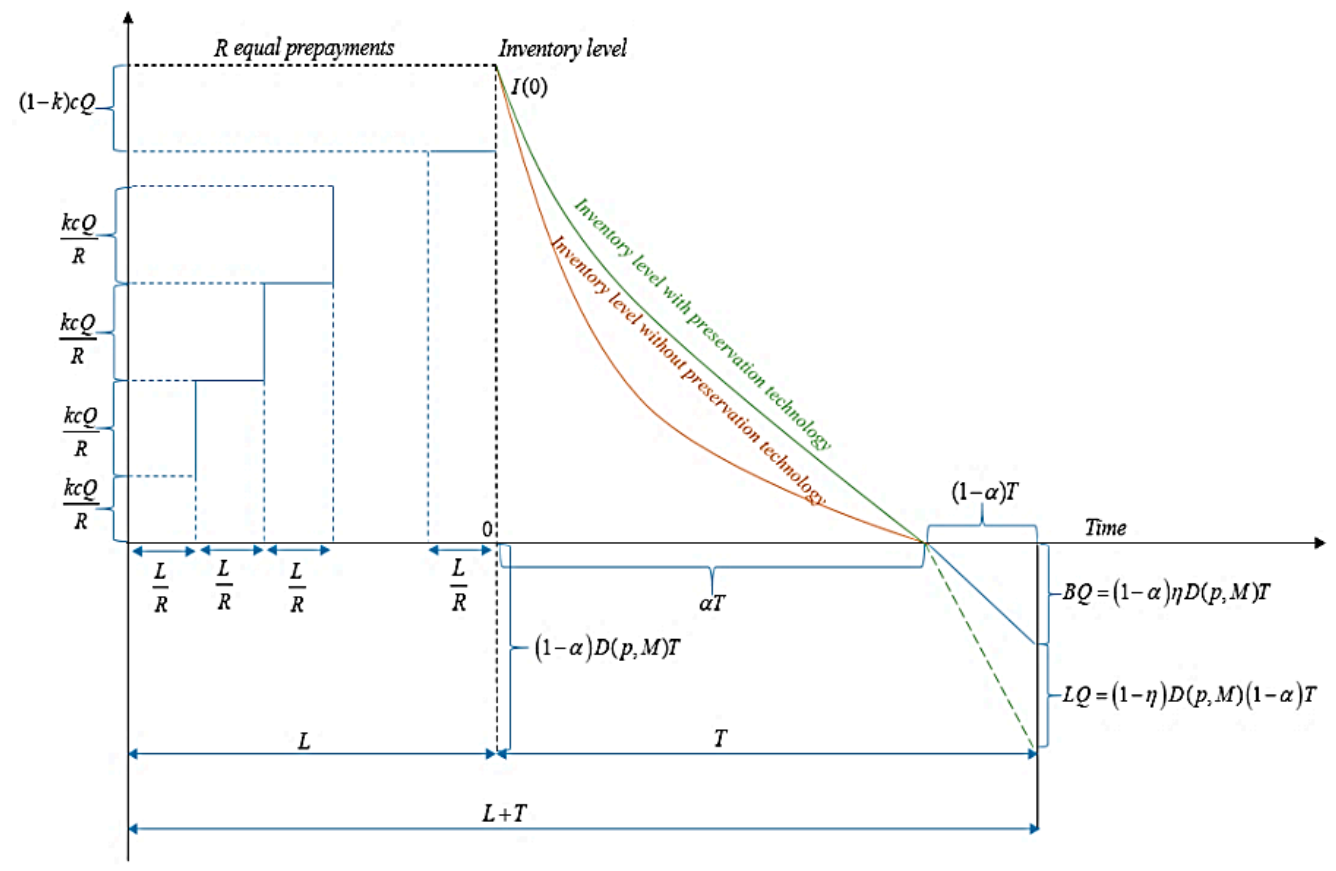

Figure 2. Sustainable supply chain inventory (SSCI) model with partial backorders.

The differential equation of the inventory level at the time $t$ is given as follows:

$$
\frac{d I(t)}{d t}=-D(p, M)-\lambda(P) I(t), \quad 0 \leq t \leq \alpha T
$$

with the boundary condition $I(\alpha T)=0$, Equation (1) yields the following solution:

$$
I(t)=\frac{D(p, M)}{\lambda(P)}\left(e^{\lambda(P)(\alpha T-t)}-1\right)
$$

The partial backorder quantity is $B Q=\eta D(p, M)(1-\alpha) T$, for $0<\eta<1$, and lost sales quantity is $L Q=(1-\eta) D(p, M)(1-\alpha) T$, for $0<\eta<1$. Thus, the order quantity per cycle length is given as

$$
Q=I(0)+\eta D(p, M)(1-\alpha) T=\frac{D(p, M)}{\lambda(P)}\left(e^{\lambda(P)(\alpha T)}-1\right)+\eta D(p, M)(1-\alpha) T
$$

The following components comprise the total annual profit.

The total discounted retailer's sales revenue given a default risk is given as follows:

$$
\begin{aligned}
D S R D & =\frac{p e^{-r M} D(p, M)[1-F(M)][\alpha T+\eta(1-\alpha) T]}{T} \\
& =p e^{-r M} D(p, M)[1-F(M)][\alpha+\eta(1-\alpha)]
\end{aligned}
$$

The ordering cost is

$$
\mathrm{OC}=\frac{A}{T}
$$

Per replenishment cycle, the cost of purchasing products follows:

$$
P C=\frac{c Q}{T}=\frac{c}{T}\left[\frac{D(p, M)}{\lambda(P)}\left(e^{\lambda(P)(\alpha T)}-1\right)+\eta D(p, M)(1-\alpha) T\right]
$$

During the interval $[0, \alpha T]$, the holding cost is presented as follows: 


$$
H C=\frac{h D(p, M)}{T} \int_{0}^{\alpha T} I(t) d t=\frac{h D(p, M)}{T}\left[\frac{\left(e^{\lambda(P) \alpha T}-\lambda(P) \alpha T-1\right)}{\lambda(P)^{2}}\right]
$$

The capital cost per cycle is as follows:

$$
C C=\frac{l k c(R+1) L}{2 R}\left[\frac{D(p, M)}{\lambda(P)}\left(e^{\lambda(P)(\alpha T)}-1\right)+\eta D(p, M)(1-\alpha) T\right]
$$

In this study, we determined the cost of the retailer's capital investment due to delayed payment. If the retailer's time limit is $M$ and the cycle time is $\alpha T$, then two situations are considered: (1) $\alpha T<M$ and (2) $\alpha T>M$ [22]. Therefore, the yearly cost of capital investment due to delayed payment is

$$
\begin{aligned}
C C D & =\frac{c l}{T}\left[\mu \int_{0}^{M} D(p, M) t d t+\int_{M}^{\alpha T} D(p, M) t d t+(1-\mu) \int_{\alpha T}^{\alpha T+M} D(p, M) t d t\right] \\
& =c l D(p, M)\left(\frac{(1-\mu)}{2} \alpha^{2} T+(1-\mu) \alpha M+\mu \frac{\alpha^{2} T}{2}\right)
\end{aligned}
$$

The backorder cost per cycle is

$$
B C=\frac{f \eta D(p, M)(1-\alpha)^{2} T^{2}}{2 T}=\frac{f \eta D(p, M)(1-\alpha)^{2} T}{2}
$$

The lost sales cost per cycle is

$$
C L S=\frac{s(1-\eta) D(p, M)(1-\alpha) T}{T}=s(1-\eta) D(p, M)(1-\alpha)
$$

The PRT investment for controlling the deterioration rate is

$$
P T C=\frac{P T}{T}=P
$$

The cost of carbon emissions comprises replenishment, storage, and environmental impact costs. The delivery frequency for replenishment is given by

$$
F D=\frac{B}{T}
$$

Storage is

$$
S M=\frac{g D(p, M)}{T} \int_{0}^{\alpha T} I(t) d t=\frac{g D(p, M)}{T}\left[\frac{\left(e^{\lambda(P) \alpha T}-\lambda(P) \alpha T-1\right)}{\lambda(P)^{2}}\right]
$$

Environment impact is

$$
E I=\frac{K Q}{T}=\frac{K}{T}\left[\frac{D(p, M)}{\lambda(P)}\left(e^{\lambda(P)(\alpha T)}-1\right)+\eta D(p, M)(1-\alpha) T\right]
$$

The maximum amount of carbon that can be entered into the carbon trading market is

$$
C L=\frac{w \delta T}{T}=w \delta
$$

Annual carbon emissions during the cycle are 


$$
\begin{aligned}
E C & =\frac{B}{T}+\frac{g D(p, M)}{T}\left[\frac{\left(e^{\lambda(P) \alpha T}-\lambda(P) \alpha T-1\right)}{\lambda(P)^{2}}\right] \\
& +\frac{K}{T}\left[\frac{D(p, M)}{\lambda(P)}\left(e^{\lambda(P)(\alpha T)}-1\right)+\eta D(p, M)(1-\alpha) T\right]
\end{aligned}
$$

Capital investment in green technology is presented as follows:

$$
\left[\theta e^{-m G}+(1-\theta)\right] E C=\left[1-\theta\left(1-e^{-m G}\right)\right] E C
$$

The total annual carbon tax per unit time in a cycle is

$$
C T=\delta\left[1-\theta\left(1-e^{-m G}\right)\right] E C
$$

The GRT investment for controlling the emission rate is

$$
G T C=\frac{G T}{T}=G
$$

Taking these items together, the annual profit is

$T P(T, \alpha, P, G, p)=D S R D-O C-P C-H C-C C-C C D-B C-C L S-P T C-C T-G T C+C L$

Therefore, the following nonlinear optimization problem is established:

$$
\begin{gathered}
\text { Max } \quad T P(T, \alpha, P, G, p) \\
\text { s.t } D(p, M)>0 \\
T>0,0<\alpha<1 \\
P>0, G>0, p>0
\end{gathered}
$$

For small values of $\lambda(P)$ and $\alpha T$, the Taylor series expansion $e^{\lambda(P) \alpha T} \approx 1+\lambda(P) \alpha T+$ $\frac{[\lambda(P) \alpha T]^{2}}{2}$ can be substituted into Equation $(21)[37,43]$. Then, the objective function is reformulated as

$$
\begin{aligned}
& T P(T, \alpha, P, G, p)=p e^{-r M} D(p, M)[1-F(M)][\alpha+\eta(1-\alpha)]-\frac{A}{T} \\
& -c D(p, M)\left(\alpha+\frac{\alpha^{2} T}{2}\left(\lambda_{0} e^{-u P}\right)+\eta(1-\alpha)\right)-h D(p, M) \frac{\alpha^{2} T}{2} \\
& -\frac{l k c(R+1) L D(p, M)}{2 R}\left(\alpha+\frac{\alpha^{2} T}{2}\left(\lambda_{0} e^{-u P}\right)+\eta(1-\alpha)\right) \\
& -c l D(p, M)\left(\frac{(1-\mu)}{2} \alpha^{2} T+(1-\mu) \alpha M+\mu \frac{\alpha^{2} T}{2}\right) \\
& -\frac{f \eta D(p, M)(1-\alpha)^{2} T}{2}-s(1-\eta) D(p, M)(1-\alpha)-P-G+w \delta \\
& -\delta\left(\frac{B}{T}+\frac{g D(p, M) \alpha^{2} T}{2}+K D(p, M)\left(\alpha+\frac{\alpha^{2} T}{2}\left(\lambda_{0} e^{-u P}\right)+\eta(1-\alpha)\right)\right)\left(1-\theta\left(1-e^{-m G}\right)\right)
\end{aligned}
$$

Because $T P(T, \alpha, P, G, p)$ is nonlinear, concavity cannot be jointly proven for $T, \alpha, P, G, p$. Because the primary focus of this study was to evaluate $P$ and $G$, we only proved the concavity for $P$ and $G$, and all other variables were kept constant.

Theorem 1. The profit function in Equation (22) is concave with regard to $P$ and $G$ for fixed $T, \alpha$, and $p$.

Proof. See Appendix B.

Let $D(p, M)=(a-b p) e^{\zeta M}$ and $F(M)=1-e^{-\phi M}$. By optimizing the objective function with regard to $T, \alpha, P, G$, and $p$, the optimum values of $T, \alpha, P, G$, and $p$ can be attained as follows:

$$
\begin{aligned}
& \frac{\partial T P(T, \alpha, P, G, p)}{\partial T}=0 ; \quad \frac{\partial T P(T, \alpha, P, G, p)}{\partial \alpha}=0 ; \frac{\partial T P(T, \alpha, P, G, p)}{\partial P}=0 \\
& \frac{\partial T P(T, \alpha, P, G, p)}{\partial G}=0 ; \& \frac{\partial T P(T, \alpha, P, G, p)}{\partial p}=0
\end{aligned}
$$




\subsection{SSCI Model with Full Backorders}

For this model, all derivations are the same as those in Section 3.1, except that $\eta=1$. Therefore, $C L S=0$. Hence, Equation (22) can be rewritten for this model as follows:

$$
\begin{aligned}
& T P(T, \alpha, P, G, p)=p e^{-r M} D(p, M)[1-F(M)][\alpha+(1-\alpha)]-\frac{A}{T} \\
& -c D(p, M)\left(\alpha+\frac{\alpha^{2} T}{2}\left(\lambda_{0} e^{-u P}\right)+(1-\alpha)\right)-h D(p, M) \frac{\alpha^{2} T}{2} \\
& -\frac{l k c(R+1) L D(p, M)}{2 R}\left(\alpha+\frac{\alpha^{2} T}{2}\left(\lambda_{0} e^{-u P}\right)+(1-\alpha)\right) \\
& -c l D(p, M)\left(\frac{(1-\mu)}{2} \alpha^{2} T+(1-\mu) \alpha M+\mu \frac{\alpha^{2} T}{2}\right) \\
& -\frac{f D(p, M)(1-\alpha)^{2} T}{2}-P-G+w \delta \\
& -\delta\left(\frac{B}{T}+\frac{g D(p, M) \alpha^{2} T}{2}+K D(p, M)\left(\alpha+\frac{\alpha^{2} T}{2}\left(\lambda_{0} e^{-u P}\right)+(1-\alpha)\right)\right)\left(1-\theta\left(1-e^{-m G}\right)\right)
\end{aligned}
$$

Theorem 2. The profit function in Equation (24) is concave with regard to $P$ and $G$ for fixed $T, \alpha$, and $p$.

Proof. See Appendix C.

Let $D(p, M)=(a-b p) e^{\zeta M}$ and $F(M)=1-e^{-\phi M}$. By optimizing the objective function with regard to $T, \alpha, P, G$, and $p$, the optimum values of $T, \alpha, P, G$, and $p$ can be obtained from the following equations:

$$
\begin{aligned}
& \frac{\partial T P(T, \alpha, P, G, p)}{\partial T}=0 ; \frac{\partial T P(T, \alpha, P, G, p)}{\partial \alpha}=0 ; \frac{\partial T P(T, \alpha, P, G, p)}{\partial P}=0 \\
& \frac{\partial T P(T, \alpha, P, G, p)}{\partial G}=0 ; \& \frac{\partial T P(T, \alpha, P, G, p)}{\partial p}=0
\end{aligned}
$$

\subsection{SSCI Model without Backorders}

For this model, all derivations are the same as those in Section 3.1, except that $\alpha=1$ and $\eta=1$. Therefore, $B C=0$ and $C L S=0$. Hence, Equation (22) can be rewritten as follows:

$$
\begin{aligned}
& T P(T, P, G, p)=p e^{-r M} D(p, M)[1-F(M)]-\frac{A}{T}-c D(p, M)\left(1+\frac{T \lambda_{0} e^{-u P}}{2}\right) \\
& -h D(p, M) \frac{T}{2}-\frac{l k c(R+1) L D(p, M)}{2 R}\left(1+\frac{T \lambda_{0} e^{-u P}}{2}\right) \\
& -c l D(p, M)\left(\frac{(1-\mu)}{2} T+(1-\mu) M+\mu \frac{T}{2}\right)-P-G \\
& +w \delta-\delta\left(\frac{B}{T}+\frac{g D(p, M) T}{2}+K D(p, M)\left(1+\frac{T \lambda_{0} e^{-u P}}{2}\right)\right)\left(1-\theta\left(1-e^{-m G}\right)\right)
\end{aligned}
$$

Theorem 3. The profit function in Equation (26) is concave with regard to $P$ and $G$ for a fixed $T$ and $p$.

Proof. See Appendix D.

Let $D(p, M)=(a-b p) e^{\zeta M}$ and $F(M)=1-e^{-\phi M}$. The objective function can be optimized with regard to $T, P, G$, and $p$ to obtain their optimum values:

$$
\begin{aligned}
& \frac{\partial T P(T, P, G, p)}{\partial T}=0 ; \frac{\partial T P(T, P, G, p)}{\partial P}=0 ; \\
& \frac{\partial T P(T, P, G, p)}{\partial G}=0 ; \& \frac{\partial T P(T, P, G, p)}{\partial p}=0
\end{aligned}
$$

\subsection{Special Cases}

- If PRT and GRT investment costs are 0, there is no carbon emissions cap, and there is no price-dependent credit demand policy, this model is the same as that introduced in [25].

- If PRT and GRT investment costs are 0 , carbon emissions are 0 , and there is no pricedependent credit demand policy, this model is the same as that in [10]. 
- If PRT and GRT investment costs are 0 and there is no carbon tax, carbon emissions cap, scrap price, goodwill loss, or price-dependent credit demand policy, this model is the same as the conventional Economic Production Quantity (EPQ) model.

\section{Real Case Background with Links to Contributions}

Carbon emissions are a factor contributing to global warming. Greenhouse managers have focused on reducing carbon emissions. Many greenhouse managers have used carbon caps and tax-based policies to achieve such reductions. Greenhouse firms must engage with regulations to reduce carbon emissions by developing a green supply chain. In a seller-buyer relationship, the seller can offer a trade credit period to the buyer to manage stock and demand changes. In a competitive marketplace, boosting demand depends on features, such as sale price, length of credit period, and customers' environmental consciousness. Item deterioration is a challenge for most firms, and it introduces time constraints. Deterioration is controllable by using PRT in greenhouse farms. The present study employed a Taiwanese greenhouse as a case study. This greenhouse trades flowers and plants using an SSCI. The greenhouse obtains orders from farmers, florists, and retailers. Flowers deteriorate rapidly under natural conditions; although this deterioration depends on time, it also involves a random element. To reduce deterioration and carbon emissions, greenhouse managers can employ PRT and GRT investment, which will reduce government taxes for high carbon emissions and mitigate global warming. Although PRT and GRT investment incurs costs for greenhouse farms, this study revealed that such investment is beneficial for both the retailer and the environment.

Moreover, suppliers can offer farmers, florists, and retailers a delayed payment period with a portion of the purchase cost prepaid as a deposit. Some numerical illustrations based on real examples reveal similar benefits for the supplier and retailer. We used the parameters and most data from Mishra et al. [40] with some revisions. We solved the proposed model using Mathematica 9 software using a $2.60 \mathrm{GHz}$ Intel Core i7 CPU with 8.00 GB of RAM.

Example 1. For partial backorders, we solved the model using Mathematica 9 through the four steps detailed as follows; data were obtained from Mishra et al. [40], with some revisions. The results are shown in Table 1.

Table 1. Optimal solutions for partial, full, and no backorders.

\begin{tabular}{cccc}
\hline Feasible Solution & Partial Backordering & Full Backordering & No Backordering \\
\hline$T$ & 5.90331 & 5.86831 & 5.43657 \\
$\alpha$ & 0.796502 & 0.851639 & NA \\
$P$ & 1.53282 & 1.55741 & 1.90784 \\
$G$ & 1.63411 & 1.65334 & 1.95667 \\
$p$ & 24.8945 & 24.9052 & 24.8995 \\
$Q$ & 0.570211 & 0.570595 & 0.597952 \\
$T P$ & 110.327 & 110.247 & 109.184 \\
\hline
\end{tabular}

NA: Not applicable.

Step 1: Set initial values

$a=100$ units, $b=4$ units, $\zeta=0.02$ unit, $A=\$ 20 /$ setup $/$ year, $c=\$ 2 /$ unit $/$ year, $\lambda_{0}=0.8$ unit $/$ year,

$u=0.8$ unit, $h=\$ 0.4 /$ unit/year, $l=\$ 0.6 /$ unit/year, $k=\$ 0.04 /$ unit/year, $R=6$ unit/order/year,

$L=0.4$ unit/order/year, $\mu=0.04$ unit/order/year, $r=0.02$ /year, $\phi=0.02$ unit, $M=0.5$ year,

$\eta=0.5$ unit, $f=\$ 40 /$ unit $/$ year, $s=\$ 0.2 /$ unit $/$ year, $\delta=\$ 0.6 / \mathrm{kg} /$ year, $w=200 \mathrm{~kg} /$ year,

$g=8 \mathrm{~kg} /$ year, $B=40 \mathrm{~kg} /$ order $/$ year, $K=10 \mathrm{~kg} /$ year, $\theta=0.4$ unit, $m=0.5$ unit.

Step 2:

Find Root $\left[\left\{\begin{array}{l}\frac{\partial T P(T, \alpha, P, G, p)}{\partial T}==0, \frac{\partial T P(T, \alpha, P, G, p)}{\partial \alpha}==0, \\ \frac{\partial T P(T, \alpha, P, G, p)}{\partial P}==0, \frac{\partial T P(T, \alpha, P, G, p)}{\partial G}==0 \\ \frac{\partial T P(T, \alpha, P, G, p)}{\partial p}==0,\end{array}\right\},\left\{\begin{array}{l}\left\{T, T_{0}\right\},\left\{\alpha, \alpha_{0}\right\}, \\ \left\{P, P_{0}\right\},\left\{G, G_{0}\right\}, \\ \left\{p, p_{0}\right\}\end{array}\right\}\right]$ 
Step 3: The output is optimal solutions $T^{*}, \alpha^{*}, P^{*}, G^{*}$, and $p^{*}$.

Step 4: Insert optimal solutions $T^{*}, \alpha^{*}, P^{*}, G^{*}$, and $p^{*}$ into Equation (22) to obtain the total profit $Q=(a-b p) e^{\zeta M}\left(\alpha+\frac{\alpha^{2} T}{2}\left(\lambda_{0} e^{-u * P}\right)+\eta(1-\alpha)\right)$.

Example 2: Full backorders.

Step 1: Set initial values

$$
\begin{aligned}
& a=100 \text { units, } b=4 \text { units, } \zeta=0.02 \text { unit, } A=\$ 20 / \text { setup } / \text { year, } c=\$ 2 / \text { unit } / \text { year, } \lambda_{0}=0.8 \text { unit } / \text { year, } \\
& u=0.8 \text { unit, } h=\$ 0.4 / \text { unit } / \text { year, } l=\$ 0.6 / \text { unit } / \text { year, } k=\$ 0.04 / \text { unit } / \text { year, } R=6 \text { units } / \text { order } / \text { year, } \\
& L=0.4 \text { unit/order } / \text { year, } \mu=0.04 \text { unit } / \text { order } / \text { year, } r=0.02 / \text { year, } \phi=0.02 \text { unit, } M=0.5 y e a r, \\
& f=\$ 40 / \text { unit/year, } \delta=\$ 0.6 / \mathrm{kg} / \text { year, } w=200 \mathrm{~kg} / \text { year, } g=8 \mathrm{~kg} / \text { year, } B=40 \mathrm{~kg} / \mathrm{order} / \text { year, } \\
& K=10 \mathrm{~kg} / \text { year, } \theta=0.4 \text { unit, } m=0.5 \text { unit. }
\end{aligned}
$$

Step 2:

$$
\text { Find Root }\left[\left\{\begin{array}{l}
\frac{\partial T P(T, \alpha, P, G, p)}{\partial T}==0, \frac{\partial T P(T, \alpha, P, G, p)}{\partial P}==0, \\
\frac{\partial T P(T, \alpha, P, G, p)}{\partial G}==0, \frac{\partial T P(T, \alpha, P, G, p)}{\partial p}==0
\end{array}\right\},\left\{\begin{array}{l}
\left\{T, T_{0}\right\},\left\{P, P_{0}\right\} \\
,\left\{G, G_{0}\right\},\left\{p, p_{0}\right\}
\end{array}\right\}\right]
$$

Step 3: The output is optimal solutions $T^{*}, \alpha^{*}, P^{*}, G^{*}$, and $p^{*}$.

Step 4: Insert optimal solutions $T^{*}, \alpha^{*}, P^{*}, G^{*}$, and $p^{*}$ into Equation (24) to obtain the total profit $Q=(a-b p) e^{\zeta M}\left(\alpha+\frac{\alpha^{2} T}{2}\left(\lambda_{0} e^{-u * P}\right)+(1-\alpha)\right)$.

Example 3. No backorders.

Step 1: Set initial values

$$
\begin{aligned}
& a=100 \text { units, } b=4 \text { units, } \zeta=0.02 \text { unit, } A=\$ 20 / \text { setup } / \text { year, } c=\$ 2 / \text { unit } / \text { year, } \lambda_{0}=0.8 \text { unit } / \text { year, } \\
& u=0.8 \text { unit, } h=\$ 0.4 / \text { unit } / \text { year, } l=\$ 0.6 / \text { unit } / \text { year, } k=\$ 0.04 / \text { unit } / \text { year, } R=6 \text { units } / \text { order } / \text { year, } \\
& L=0.4 \text { unit } / \text { order } / \text { year, } \mu=0.04 \text { unit } / \text { order } / \text { year, } r=0.02 / \text { year, } \phi=0.02 \text { unit, } M=0.5 y e a r, \\
& \delta=\$ 0.6 / \mathrm{kg} / \text { year, } w=200 \mathrm{~kg} / \text { year, } g=8 \mathrm{~kg} / \text { year, } B=40 \mathrm{~kg} / \text { order } / \text { year, } K=10 \mathrm{~kg} / \text { year, } \\
& \theta=0.4 \text { unit, } m=0.5 \text { unit. }
\end{aligned}
$$

Step 2:

Find Root $\left[\left\{\begin{array}{l}\frac{\partial T P(T, \alpha, P, G, p)}{\partial T}==0, \frac{\partial T P(T, \alpha, P, G, p)}{\partial \alpha}==0, \\ \frac{\partial T P(T, \alpha, P, G, p)}{\partial P}==0, \frac{\partial T P(T, \alpha, P, G, p)}{\partial P}==0, \\ \frac{\partial T P(T, \alpha, P, G, p)}{\partial G}==0, \frac{\partial T P(T, \alpha, P, G, p)}{\partial p}==0\end{array}\right\},\left\{\begin{array}{l}\left\{T, T_{0}\right\},\left\{\alpha, \alpha_{0}\right\},\left\{P, P_{0}\right\} \\ ,\left\{G, G_{0}\right\},\left\{p, p_{0}\right\}\end{array}\right\}\right]$

Step 3: The output is optimal solutions $T^{*}, \alpha^{*}, P^{*}, G^{*}$, and $p^{*}$.

Step 4: Insert optimal solutions $T^{*}, \alpha^{*}, P^{*}, G^{*}$, and $p^{*}$ into Equation (26) to obtain the total profit $Q=(a-b p) e^{\zeta M}\left(1+\frac{\alpha^{2} T}{2}\left(\lambda_{0} e^{-u P}\right)\right)$.

Although the total profit is the lowest for partial backorders, this model is more accurate because it examines economic and environmental issues. Moreover, the model with full backordering is not applicable in some cases. Therefore, the model with partial backorders is conditional because a fraction of orders can be backlogged to increase profits. Table 1 indicates that the cycle time $T$ is highest for the partial backordering model. However, PRT and GRT investment ( $P$ and $G$, respectively) are lower in the partial backorder model than in the other models. The partial backorder model is an SSCI model in which product shortages influence reasonable total profits.

The concavity of the total profit function should be verified. Figures $3 a, 4 a$ and $5 a$ present contour plots for the models' total profit functions in Examples 1, 2, and 3, respectively. The global optimum profit points are represented graphically to validate the obtained solutions. 

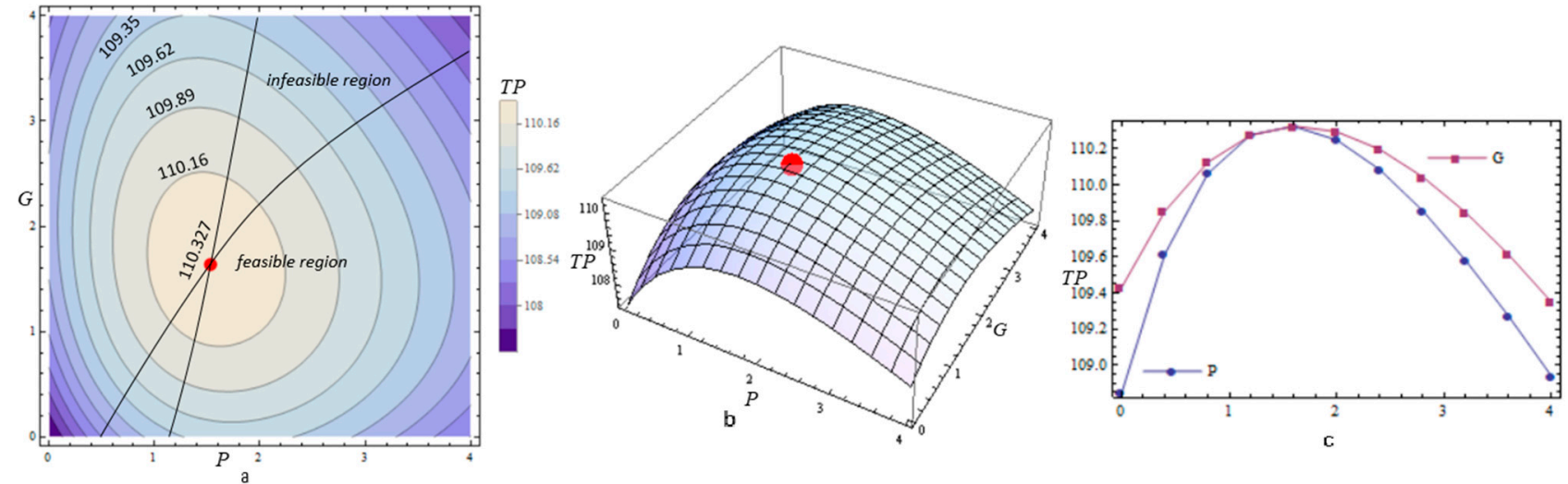

Figure 3. Partial backordering. (a) Contour plot of TP; the red dot represents the feasible point of $T P$ with regard to $P$ and $G$. (b) 3D plot showing the concavity of $T P$ with regard to $P$ and $G$. (c) Concavity of $T P$ with regard to $P$ and $G$.
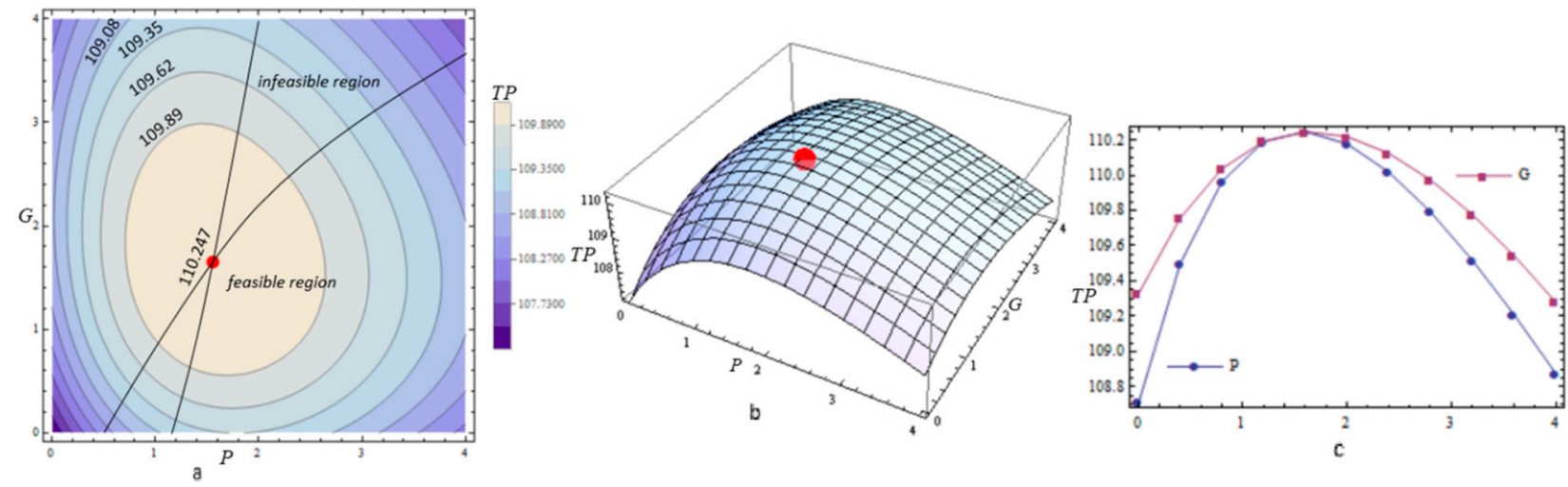

Figure 4. Full backordering. (a) Contour plot of $T P$; the red dot represents the feasible point of $T P$ with regard to $P$ and $G$. (b) 3D plot showing the concavity of $T P$ with regard to $P$ and $G$. (c) Concavity of TP with regard to $P$ and $G$.
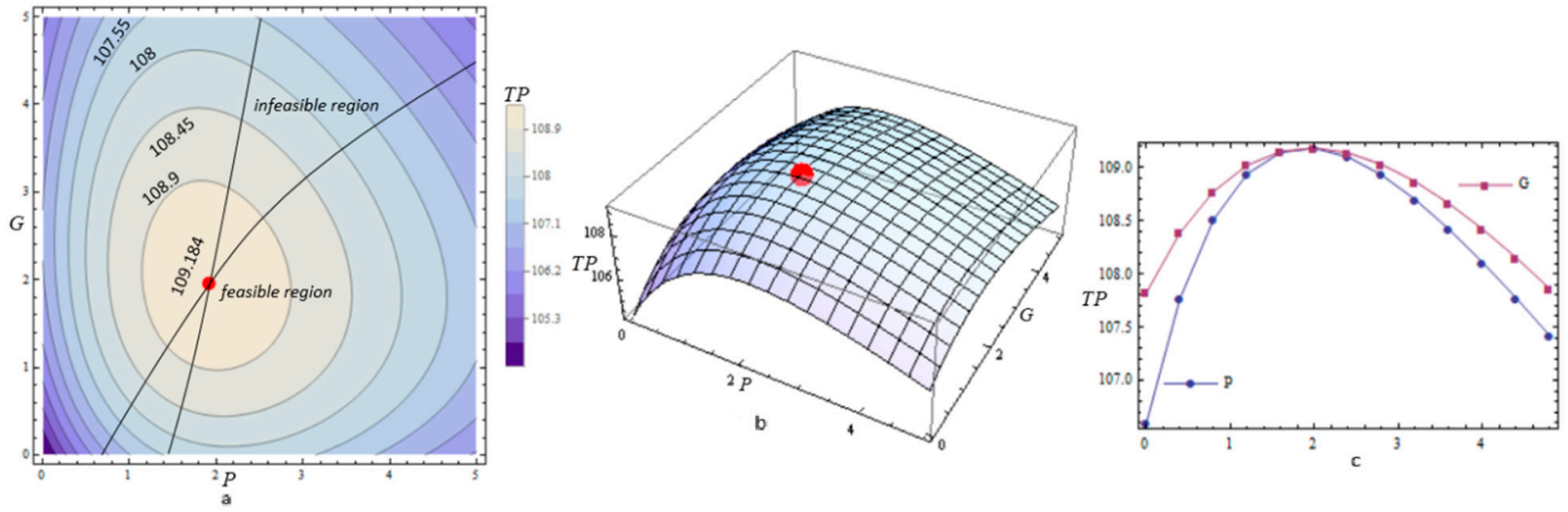

Figure 5. No backordering. (a) Contour plot of TP; the red dot represents the feasible point of $T P$ with regard to $P$ and $G$. (b) 3D plot showing the concavity of $T P$ with regard to $P$ and $G$. (c) Concavity of $T P$ with regard to $P$ and $G$.

These contour plots illustrate that the profit functions are concave, with congregation toward a distinct point. Figures $3 \mathrm{~b}, 4 \mathrm{~b}$ and $5 \mathrm{~b}$ present $3 \mathrm{D}$ plots of total profit functions for the models in Examples 1, 2, and 3, respectively. These plots illustrate that these functions are concave with regard to $P$ and $G$. As a result, the local maxima of $T P$ are the global maxima. Figures $3 c, 4 c$ and $5 \mathrm{c}$ unambiguously indicate that total profit is minimized at $P=0$ and $G=0$. The point at which the lines representing $P$ and $G$ meet is the optimal point at which total profit is maximized. 
Consequently, retailers should employ capital investment for $P$ and $G$ to maximize profit. The effects of critical parameters should be investigated by increasing and decreasing them while monitoring total profit.

\section{Sensitivity Analysis and Managerial Implications}

This section presents a sensitivity analysis for different parameters for full backorder, partial backorder, and no backorder cases to validate the proposed model in Section 5.1, while in Section 5.2 some managerial implications have been presented.

\subsection{Sensitivity Analysis}

A sensitivity analysis has been carried out in this section to show the proposed model's flexibility and presents the effects of some critical parameters on the anticipated three different cases named full backorder, partial backorder, and no backorder (Table 2).

The results of the sensitivity analysis (Table 2) are summarized in the following remarks:

1. In all models, the total profit, order quantity, cycle time, and selling price increase with an increase in demand scale parameters. This shows that intensifying demand increases profits. PRT and GRT costs decline with increases in demand scale parameters. The values of positive inventory level decrease with increases in the demand scale parameters during a surge in backorders.

2. When the price sensitivity increases, the total profit, selling price shrinkage, and cycle time values also increase. That is, the higher the price sensitivity is, the lower the annual profit is. The PRT cost, GRT cost, and order quantity increase with increases in price sensitivity; moreover, the positive inventory level increases with price sensitivity in backorder models.

3. With the increase of trade credit period, the total profit, selling price, and cycle time decrease, and PRT cost, GRT cost, and order quantity increase. That is, the longer the trade credit period is, the lower the annual profit is. Furthermore, the positive inventory level decreases when the credit period increases in the backorder model.

4. If the prepayment period decreases, then the total profit and cycle time increase, and at the same time the order quantity and the PRT and GRT costs increase. This is because the longer the prepayment period, then the higher the annual profit. Moreover, the positive inventory level increases when the prepayment period increases in backorder models.

5. When the purchasing cost for advance payments increases, the total profit and cycle time increase, and PRT cost, GRT cost, order quantity, and selling price decrease. That is, the higher the fraction of purchasing cost is, the lower the annual profit is. Additionally, a positive inventory level decreases with increases in purchasing cost in backorder models.

6. For all three cases, when the discount rate increases, the suppliers' lead time, carbon emissions, total profit, cycle time, and selling price decrease, and the PRT cost, GRT cost, and order quantity increase. Moreover, the positive inventory level increases when the discount rate, suppliers' lead time, and carbon emissions increase in backorder models.

7. The increase of fixed ordering cost and carbon emissions related to ordering leads to a decrease in the total profit and selling price, and the cycle time, PRT cost, GRT cost, and order quantity increase. The positive inventory level increases when the fixed ordering cost and carbon emissions related to ordering increase in backorder models.

8. The table shows that when the purchasing cost increases, the total profit, cycle time, and selling price decrease, and the PRT cost, GRT cost, and order quantity increase. The positive inventory level decreases when the purchasing cost increases in backorder models.

9. The increase in the retailer's revenue raises the sensitive parameter for PRT investment and the sensitive parameter for investment to carbon emissions. The total profit, cycle 
time, and selling price increase, and the PRT cost, GRT cost, and order quantity plummet. The positive inventory level increases when the sensitive parameters for PRT investment and investment in carbon emission alleviation increase in backorder models.

Table 2. Sensitivity analysis of critical parameters.

\begin{tabular}{|c|c|c|c|c|c|c|c|c|}
\hline Parameters & $\begin{array}{l}\text { Feasible } \\
\text { Solution }\end{array}$ & $\begin{array}{c}\text { Partial } \\
\text { Backorder }\end{array}$ & $\begin{array}{c}\text { Full } \\
\text { Backorder }\end{array}$ & $\begin{array}{c}\text { No } \\
\text { Backorder }\end{array}$ & $\begin{array}{l}\text { Feasible } \\
\text { Solution }\end{array}$ & $\begin{array}{c}\text { Partial } \\
\text { Backorder }\end{array}$ & $\begin{array}{c}\text { Full } \\
\text { Backorder }\end{array}$ & $\begin{array}{c}\text { No } \\
\text { Backorder }\end{array}$ \\
\hline \multirow{8}{*}{$a$} & \multicolumn{4}{|c|}{$a=97$} & \multicolumn{4}{|c|}{$a=106$} \\
\hline & $T$ & 5.7275 & 5.69393 & 5.26978 & $T$ & 6.24368 & 6.20608 & 5.76034 \\
\hline & $\alpha$ & 0.798766 & 0.853312 & NA & $\alpha$ & 0.79205 & 0.848324 & NA \\
\hline & $P$ & 1.57811 & 1.60204 & 1.94959 & $P$ & 1.44806 & 1.47383 & 1.83013 \\
\hline & G & 1.71384 & 1.73249 & 2.03504 & G & 1.4868 & 1.507 & 1.81198 \\
\hline & $p$ & 24.1372 & 24.1485 & 24.1422 & $p$ & 26.4069 & 26.4165 & 26.4118 \\
\hline & $Q$ & 0.494573 & 0.598858 & 0.628516 & $Q$ & 0.522067 & 0.52273 & 0.546247 \\
\hline & $\widetilde{T P}$ & 109.724 & 109.956 & 108.875 & $\widetilde{T P}$ & 110.855 & 110.776 & 109.743 \\
\hline \multirow{8}{*}{$b$} & \multicolumn{4}{|c|}{$b=3$} & \multicolumn{4}{|c|}{$b=6$} \\
\hline & $T$ & 7.63133 & 7.58574 & 7.09339 & $T$ & 3.70824 & 3.69422 & 3.37288 \\
\hline & $\alpha$ & 0.772954 & 0.833774 & NA & $\alpha$ & 0.822921 & 0.870532 & NA \\
\hline & $P$ & 1.13435 & 1.16399 & 1.54822 & $P$ & 2.20346 & 2.21734 & 2.5408 \\
\hline & G & 0.963842 & 0.986423 & 1.29942 & G & 2.88753 & 2.8948 & 3.19449 \\
\hline & $p$ & 33.2543 & 33.2632 & 33.2602 & $p$ & 16.4729 & 16.4909 & 16.4752 \\
\hline & $Q$ & 0.388546 & 0.389172 & 0.403821 & $Q$ & 1.27269 & 1.26759 & 1.36541 \\
\hline & $\widetilde{T P}$ & 112.634 & 112.557 & 111.612 & $\widetilde{T P}$ & 105.225 & 105.148 & 103.707 \\
\hline \multirow{8}{*}{$M$} & \multicolumn{4}{|c|}{$M=0.1$} & \multicolumn{4}{|c|}{$M=5$} \\
\hline & $T$ & 6.09458 & 6.05558 & 5.62562 & $T$ & 3.4844 & 3.53259 & 3.02453 \\
\hline & $\alpha$ & 0.795772 & 0.85162 & NA & $\alpha$ & 0.791712 & 0.837694 & NA \\
\hline & $P$ & 1.48975 & 1.51684 & 1.86195 & $P$ & 2.12201 & 2.15287 & 2.68365 \\
\hline & G & 1.55351 & 1.57523 & 1.87104 & G & 2.99741 & 2.93468 & 3.48939 \\
\hline & $p$ & 24.9009 & 24.9109 & 24.9062 & $p$ & 24.6959 & 24.7411 & 24.6683 \\
\hline & $Q$ & 0.542839 & 0.543541 & 0.5667 & $Q$ & 1.40768 & 1.34727 & 1.67362 \\
\hline & $\widetilde{T P}$ & 110.623 & 110.538 & 109.518 & $\widetilde{T P}$ & 104.622 & 104.791 & 102.297 \\
\hline \multirow{8}{*}{$R$} & \multicolumn{4}{|c|}{$R=2$} & \multicolumn{4}{|c|}{$R=10$} \\
\hline & $T$ & 5.90252 & 5.66752 & 5.43582 & $T$ & 5.90347 & 5.86846 & 5.43672 \\
\hline & $\alpha$ & 0.79511 & 0.851646 & NA & $\alpha$ & 0.7965 & 0.851638 & NA \\
\hline & $P$ & 1.53363 & 1.55822 & 1.90865 & $P$ & 1.53266 & 1.55725 & 1.90768 \\
\hline & G & 1.63437 & 1.6536 & 1.95693 & $G$ & 1.63406 & 1.65329 & 1.95662 \\
\hline & $p$ & 24.8945 & 24.9051 & 24.8995 & $p$ & 24.8945 & 24.9052 & 24.8995 \\
\hline & $Q$ & 0.569114 & 0.571053 & 0.597802 & $Q$ & 0.570238 & 0.570623 & 0.597982 \\
\hline & $\widetilde{T P}$ & 110.325 & 110.245 & 109.182 & $\widetilde{T P}$ & 110.328 & 110.248 & 109.185 \\
\hline \multirow{8}{*}{$k$} & \multicolumn{4}{|c|}{$k=0.01$} & \multicolumn{4}{|c|}{$k=0.07$} \\
\hline & $T$ & 5.90539 & 5.87037 & 5.43853 & $T$ & 5.90124 & 5.86625 & 5.443461 \\
\hline & $\alpha$ & 0.796477 & 0.851621 & NA & $\alpha$ & 0.796526 & 0.891657 & NA \\
\hline & $P$ & 1.5307 & 1.55529 & 1.90573 & $P$ & 1.53494 & 1.55952 & 1.90995 \\
\hline & G & 1.63344 & 1.65268 & 1.95599 & G & 1.63478 & 1.65401 & 1.95735 \\
\hline & $p$ & 24.8246 & 24.9052 & 24.8996 & $p$ & 24.8944 & 24.9051 & 24.8994 \\
\hline & $Q$ & 0.570037 & 0.570971 & 0.59775 & $Q$ & 0.570384 & 0.570822 & 0.59814 \\
\hline & $\widetilde{T P}$ & 110.332 & 110.252 & 109.189 & $\widetilde{T P}$ & 110.321 & 110.242 & 109.179 \\
\hline \multirow{8}{*}{$r$} & \multicolumn{4}{|c|}{$r=0.01$} & \multicolumn{4}{|c|}{$r=0.03$} \\
\hline & $T$ & 5.93207 & 5.89686 & 5.46389 & $T$ & 5.8746 & 5.8398 & 5.4093 \\
\hline & $\alpha$ & 0.796131 & 0.851362 & NA & $\alpha$ & 0.796871 & 0.85194 & NA \\
\hline & $P$ & 1.52552 & 1.5502 & 1.90112 & $P$ & 1.54014 & 1.56463 & 1.91458 \\
\hline & $G$ & 1.62132 & 1.64063 & 1.94409 & $G$ & 1.64695 & 1.66611 & 1.9693 \\
\hline & $p$ & 24.8956 & 24.9062 & 24.9006 & $p$ & 24.8933 & 24.9041 & 24.8984 \\
\hline & $Q$ & 0.566007 & 0.566436 & 0.59339 & $Q$ & 0.74927 & 0.575328 & 0.602486 \\
\hline & $\widetilde{T P}$ & 110.374 & 110.294 & 109.234 & $\widetilde{T P}$ & 110.28 & 110.20 & 109.134 \\
\hline
\end{tabular}


Table 2. Cont.

\begin{tabular}{|c|c|c|c|c|c|c|c|c|}
\hline Parameters & $\begin{array}{l}\text { Feasible } \\
\text { Solution }\end{array}$ & $\begin{array}{c}\text { Partial } \\
\text { Backorder }\end{array}$ & $\begin{array}{c}\text { Full } \\
\text { Backorder }\end{array}$ & $\begin{array}{c}\text { No } \\
\text { Backorder }\end{array}$ & $\begin{array}{l}\text { Feasible } \\
\text { Solution }\end{array}$ & $\begin{array}{c}\text { Partial } \\
\text { Backorder }\end{array}$ & $\begin{array}{c}\text { Full } \\
\text { Backorder }\end{array}$ & $\begin{array}{c}\text { No } \\
\text { Backorder }\end{array}$ \\
\hline \multirow{8}{*}{$\mu$} & \multicolumn{4}{|c|}{$\mu=0.01$} & \multicolumn{4}{|c|}{$\mu=0.07$} \\
\hline & $T$ & 5.89936 & 5.86449 & 5.43253 & $T$ & 5.90727 & 5.87212 & 5.44061 \\
\hline & $\alpha$ & 0.796482 & 0.851603 & NA & $\alpha$ & 0.796521 & 0.851675 & NA \\
\hline & $P$ & 1.53363 & 1.55812 & 1.90884 & $P$ & 1.53202 & 1.5567 & 1.90684 \\
\hline & G & 1.63574 & 1.65488 & 1.95854 & $G$ & 1.63248 & 1.65181 & 1.9548 \\
\hline & $p$ & 24.8943 & 24.905 & 24.8993 & $p$ & 24.8946 & 24.9053 & 24.8997 \\
\hline & $Q$ & 0.571031 & 0.571554 & 0.598846 & $Q$ & 0.569929 & 0.570237 & 0.597058 \\
\hline & $\widetilde{T P}$ & 110.321 & 110.241 & 109.177 & $\widetilde{T P}$ & 110.333 & 110.253 & 109.191 \\
\hline \multirow{8}{*}{$L$} & \multicolumn{4}{|c|}{$L=0.1$} & \multicolumn{4}{|c|}{$L=0.7$} \\
\hline & $T$ & 5.90539 & 5.86625 & 5.43461 & $T$ & 5.90124 & 5.86625 & 5.43461 \\
\hline & $\alpha$ & 0.796477 & 0.851657 & NA & $\alpha$ & 0.796526 & 0.851657 & NA \\
\hline & $P$ & 1.5307 & 1.55952 & 1.90995 & $P$ & 1.53494 & 1.55952 & 1.90995 \\
\hline & G & 1.63344 & 1.65401 & 1.95735 & G & 1.63478 & 1.65401 & 1.95735 \\
\hline & $p$ & 24.8946 & 24.9051 & 24.8994 & $p$ & 24.8944 & 24.9051 & 24.8994 \\
\hline & $Q$ & 0.570037 & 0.570822 & 0.598154 & $Q$ & 0.570381 & 0.570822 & 0.598154 \\
\hline & $T P$ & 110.332 & 110.252 & 109.189 & $T P$ & 110.322 & 110.242 & 109.179 \\
\hline \multirow{8}{*}{$A$} & \multicolumn{4}{|c|}{$A=10$} & \multicolumn{4}{|c|}{$A=30$} \\
\hline & $T$ & 5.44535 & 5.41477 & 5.04498 & $T$ & 6.24394 & 6.20587 & 5.7277 \\
\hline & $\alpha$ & 0.781478 & 0.839932 & NA & $\alpha$ & 0.806245 & 0.859162 & NA \\
\hline & $P$ & 1.16823 & 1.19473 & 1.57226 & $P$ & 1.80915 & 1.83253 & 2.16731 \\
\hline & $G$ & 1.42799 & 1.44572 & 1.72507 & G & 1.83919 & 1.85933 & 2.17887 \\
\hline & $p$ & 24.9127 & 24.9223 & 24.9186 & $p$ & 24.8766 & 24.8885 & 24.8809 \\
\hline & $Q$ & 0.498441 & 0.498366 & 0.517536 & $Q$ & 0.640636 & 0.64103 & 0.675883 \\
\hline & $\widetilde{T P}$ & 112.086 & 112.017 & 111.089 & $\widetilde{T P}$ & 108.682 & 108.592 & 107.394 \\
\hline \multirow{8}{*}{$c$} & \multicolumn{4}{|c|}{$c=1$} & \multicolumn{4}{|c|}{$c=3$} \\
\hline & $T$ & 6.71478 & 6.67873 & 6.28506 & $T$ & 5.19354 & 5.16164 & 4.70363 \\
\hline & $\alpha$ & 0.808554 & 0.861595 & NA & $\alpha$ & 0.784755 & 0.841727 & NA \\
\hline & $P$ & 1.30184 & 1.32696 & 1.64211 & $P$ & 1.74436 & 1.76754 & 2.15447 \\
\hline & $G$ & 1.47934 & 1.49956 & 1.77232 & $G$ & 1.81413 & 1.8314 & 2.16735 \\
\hline & $p$ & 24.9132 & 24.9214 & 24.9182 & $p$ & 24.8713 & 24.8852 & 24.8759 \\
\hline & $Q$ & 0.534454 & 0.535407 & 0.553845 & $Q$ & 0.628799 & 0.628794 & 0.669706 \\
\hline & $T P$ & 111.44 & 111.368 & 110.509 & $T P$ & 109.13 & 109.044 & 107.735 \\
\hline \multirow{8}{*}{$u$} & \multicolumn{4}{|c|}{$u=0.7$} & \multicolumn{4}{|c|}{$u=0.9$} \\
\hline & $T$ & 5.75024 & 5.71777 & 5.31594 & $T$ & 6.02552 & 5.98851 & 5.53336 \\
\hline & $\alpha$ & 0.791236 & 0.847545 & NA & $\alpha$ & 0.800529 & 0.854761 & NA \\
\hline & $P$ & 1.53552 & 1.56462 & 1.98092 & $P$ & 1.50877 & 1.53003 & 1.83216 \\
\hline & G & 1.68162 & 1.70043 & 2.00134 & G & 1.59699 & 1.61653 & 1.92155 \\
\hline & $p$ & 24.8918 & 24.903 & 24.8975 & $p$ & 24.8965 & 24.9068 & 24.901 \\
\hline & $Q$ & 0.606392 & 0.610038 & 0.634188 & $Q$ & 0.542577 & 0.542831 & 0.57018 \\
\hline & $T P$ & 110.122 & 110.038 & 108.924 & $T P$ & 110.506 & 110.429 & 109.404 \\
\hline \multirow{8}{*}{ B } & \multicolumn{4}{|c|}{$B=20$} & \multicolumn{4}{|c|}{$B=60$} \\
\hline & $T$ & 5.2851 & 5.25694 & 4.92082 & $T$ & 6.31829 & 6.27874 & 5.78341 \\
\hline & $\alpha$ & 0.778797 & 0.837751 & NA & $\alpha$ & 0.807136 & 0.85988 & NA \\
\hline & $P$ & 1.27232 & 1.29852 & 1.67647 & $P$ & 1.74232 & 1.76586 & 2.10041 \\
\hline & G & 1.01767 & 1.03722 & 1.36052 & G & 2.07393 & 2.09301 & 2.38839 \\
\hline & $p$ & 24.9053 & 24.9158 & 24.912 & $p$ & 24.8828 & 24.894 & 24.8867 \\
\hline & $Q$ & 0.517572 & 0.517843 & 0.538566 & $Q$ & 0.621287 & 0.621901 & 0.643662 \\
\hline & $\widetilde{T P}$ & 112.049 & 111.975 & 110.972 & $\widetilde{T P}$ & 108.841 & 108.755 & 107.615 \\
\hline
\end{tabular}


Table 2. Cont

\begin{tabular}{|c|c|c|c|c|c|c|c|c|}
\hline Parameters & $\begin{array}{l}\text { Feasible } \\
\text { Solution }\end{array}$ & $\begin{array}{c}\text { Partial } \\
\text { Backorder }\end{array}$ & $\begin{array}{c}\text { Full } \\
\text { Backorder }\end{array}$ & $\begin{array}{c}\text { No } \\
\text { Backorder }\end{array}$ & $\begin{array}{l}\text { Feasible } \\
\text { Solution }\end{array}$ & $\begin{array}{c}\text { Partial } \\
\text { Backorder }\end{array}$ & $\begin{array}{c}\text { Full } \\
\text { Backorder }\end{array}$ & $\begin{array}{c}\text { No } \\
\text { Backorder }\end{array}$ \\
\hline \multirow{8}{*}{ K } & \multicolumn{4}{|c|}{$K=5$} & \multicolumn{4}{|c|}{$K=15$} \\
\hline & $T$ & 6.3606 & 6.32129 & 5.86134 & $T$ & 5.42973 & 5.39914 & 4.99449 \\
\hline & $\alpha$ & 0.787306 & 0.844693 & NA & $\alpha$ & 0.804666 & 0.85771 & NA \\
\hline & $P$ & 0.893462 & 0.920116 & 1.28678 & $P$ & 2.01299 & 2.03561 & 2.37547 \\
\hline & $G$ & 1.17644 & 1.19978 & 1.53758 & G & 2.08825 & 2.10372 & 2.3823 \\
\hline & $p$ & 24.9105 & 24.9199 & 24.9154 & $p$ & 24.8731 & 24.8855 & 24.8782 \\
\hline & $Q$ & 0.602173 & 0.603272 & 0.628059 & $Q$ & 0.60669 & 0.606825 & 0.639083 \\
\hline & $\widetilde{T P}$ & 111.712 & 111.63 & 110.576 & $\widetilde{T P}$ & 108.998 & 108.92 & 107.829 \\
\hline \multirow{8}{*}{$m$} & \multicolumn{4}{|c|}{$m=0.4$} & \multicolumn{4}{|c|}{$m=0.6$} \\
\hline & $T$ & 5.72976 & 5.69588 & 5.27509 & $T$ & 6.02785 & 5.99207 & 5.55268 \\
\hline & $\alpha$ & 0.793484 & 0.849199 & NA - & $\alpha$ & 0.798609 & 0.853337 & NA - \\
\hline & $P$ & 1.61272 & 1.63664 & 1.98346 & $P$ & 1.47537 & 1.50066 & 1.85394 \\
\hline & G & 1.56427 & 1.58777 & 1.96724 & G & 1.62908 & 1.64533 & 1.89779 \\
\hline & $p$ & 24.887 & 24.8987 & 24.8931 & $p$ & 24.8994 & 24.9095 & 24.9038 \\
\hline & $Q$ & 0.590718 & 0.590834 & 0.61834 & $Q$ & 0.557515 & 0.557747 & 0.584559 \\
\hline & $\widetilde{T P}$ & 109.968 & 109.884 & 108.745 & $\widetilde{T P}$ & 110.625 & 110.549 & 109.536 \\
\hline \multirow{8}{*}{$\delta$} & \multicolumn{4}{|c|}{$\delta=0.4$} & \multicolumn{4}{|c|}{$\delta=0.8$} \\
\hline & $T$ & 6.76878 & 6.73861 & 6.4004 & $T$ & 5.12635 & 5.09058 & 4.59949 \\
\hline & $\alpha$ & 0.810187 & 0.86271 & NA & $\alpha$ & 0.782239 & 0.839916 & NA \\
\hline & $P$ & 1.13302 & 1.157 & 1.46846 & $P$ & 1.8937 & 1.91829 & 2.31089 \\
\hline & $G$ & 0.54643 & 0.56425 & 0.817785 & G & 2.51878 & 2.53829 & 2.89288 \\
\hline & $p$ & 24.9234 & 24.9307 & 24.9285 & $p$ & 24.8547 & 24.8704 & 24.8588 \\
\hline & $Q$ & 0.502296 & 0.50258 & 0.517319 & $Q$ & 0.685036 & 0.685726 & 0.735719 \\
\hline & $T P$ & 73.2491 & 73.1889 & 72.447 & $T P$ & 147.307 & 147.203 & 145.697 \\
\hline \multirow{8}{*}{$u, m$} & \multicolumn{4}{|c|}{$u=0.7, m=0.4$} & \multicolumn{4}{|c|}{$u=0.9, m=0.6$} \\
\hline & $T$ & 5.59198 & 5.6034 & 5.16626 & $T$ & 6.15993 & 6.12196 & 5.65709 \\
\hline & $\alpha$ & 0.788488 & 0.845304 & NA & $\alpha$ & 0.802793 & 0.856574 & NA \\
\hline & $P$ & 1.62649 & 1.65477 & 2.06641 & $P$ & 1.45764 & 1.47932 & 1.78376 \\
\hline & $G$ & 1.61894 & 1.64197 & 2.01896 & $G$ & 1.59621 & 1.61275 & 1.86683 \\
\hline & $p$ & 24.884 & 24.8966 & 24.8912 & $p$ & 24.9016 & 24.9112 & 24.9053 \\
\hline & $Q$ & 0.627843 & 0.627844 & 0.653403 & $Q$ & 0.528376 & 0.529018 & 0.556466 \\
\hline & $T P$ & 109.752 & 109.663 & 108.474 & $T P$ & 110.798 & 110.724 & 109.75 \\
\hline
\end{tabular}

NA: Not applicable.

\subsection{Managerial Implications}

The analysis of the proposed study will help a retailer run a business smoothly and profitably. Some significant insights are:

- Total annual profit increases with reductions in deterioration and emissions. Therefore, greenhouse managers should precisely apply PRT and GRT to increase profits and protect greenhouse products (i.e., plants and flowers) and the environment. Profit increases with increases in the number of prepayments. Managers should aim to increase prepayment quantity and recurrence rate.

- Lower ordering costs and emission-linked order edge charges increase total annual profit; thus, the retailer can obtain additional profit by reducing the ordering edge value when shortages are not permitted. Moreover, higher ordering increases the inventory cycle, resulting in increased losses because of deterioration and carbon emissions. Therefore, greenhouse managers should increase PRT and GRT investment to control both deterioration and emissions.

- If ordering costs, including emissions-related ordering costs, are sufficiently low, PRT and GRT costs are zero; thus, the system becomes a conventional sustainable EOQ supply chain model with or without backorder and without investment. 
- If purchasing cost increases, the cycle time and annual profit decrease, and ordering increases. If greenhouse managers offer a maximum purchasing cost per unit, the buyer should maximize the order quantity to counter product deterioration and emissions by increasing PRT and GRT investment.

- When the sensitive parameter for PRT investment and the sensitive parameter for investment to carbon emissions increase, the cycle time, profit, and selling price increase, but the PRT cost, GRT cost, and ordering quantity decrease. Therefore, the minimum return on capital should increase.

- The optimal annual profit increases with reductions in PRT and GRT investment costs, thus reducing deterioration and carbon emissions. Furthermore, if these two parameters are sufficiently low, then PRT and GRT costs are zero. The system then becomes a conventional sustainable EOQ supply chain model with or without backorders and without investment (PRT and GRT).

- This greenhouse-based sustainable inventory model for carbon emissions, PRT and GRT investment, and emissions and deterioration rates yields an optimal solution. This study proposes a strategy for flower retailers to deal with deteriorating products. By introducing PRT and GRT investments, greenhouse retailers can maximize their profits. Furthermore, a trade-off exists between using investment and GRT for emissions reductions.

\section{Conclusions}

Carbon emissions and deterioration are factors affecting global warming. Greenhouse managers have focused on reducing carbon emissions and have used carbon caps and taxbased implications to achieve this. Studies have investigated how firms deal with carbon emission constraints because of the importance of reducing carbon emissions in developing a green supply chain. In a seller-buyer relationship, the seller can offer a trade credit period to the buyer to manage stocks and stimulate demand. Item deterioration is a challenge for many firms as it introduces specific time constraints. Deterioration is controllable by using PRT in greenhouse farms. The present study contributes to the literature by exploring greenhouse managers' need to consider PRT and GRT investment and trade credit to increase profits. This study's primary outcomes relate to annual profit, PRT and GRT investment cost, deterioration, and carbon emissions. We propose a payment scheme with prepayments and a trade credit policy, and we suggest a novel solution technique for SSCI models. This solution optimizes the total annual profit with or without inventory shortages. We used three numerical examples to validate the projected model's effectiveness (full backorder, partial backorder, and no backorder) and to explain the process. This study has observed that a full backorder case is more profitable than others.

Furthermore, if the PRT and GRT parameters are sufficiently low, PRT and GRT costs are zero, and the system is reduced to a conventional sustainable EOQ supply chain model with or without backorders and without investment (PRT and GRT). It is recommended that greenhouse managers use the proposed SSCI model and its solution technique in real-world situations. Greenhouse managers should use PRT and GRT investment and a trade credit policy to increase their total annual profits.

The proposed model and solution procedure are valuable tools for greenhouse managers. Using the proposed model, greenhouse managers can better regulate their stock in greenhouse stores with PRT and GRT investment, reducing the deterioration rate. The effects of greenhouse products (i.e., plants and flowers) on global warming can be passed on to clients through prepayments, trade credit policy, order quantity, and shortages (none, partial, or full). The proposed SSCI model also includes payment systems in a shortage (partial or full backorders) situation and a situation without shortage with a price- and credit-linked demand rate. This model's main recommendation is to invest in PRT and GRT and introduce trade credits to increase profit.

The limitation of this study is that the deterioration rate is modeled as instantaneous throughout the year. However, deterioration can be non-instantaneous due to season 
changes. Future studies could extend the proposed model for non-instantaneous deterioration rates. This study could also be improved by considering stock- and price-dependent demand in backorder cases. This study can also be extended by considering the advancecash-credit payments system. Some flowers are dried out in the greenhouse farm process, so one needs to use the waste management technique [47] to manage it, which lags in this study.

Author Contributions: Data curation and software: U.M.; formal analysis, investigation, writing original draft preparation, draft review, visualization, and editing: U.M. and A.H.M.M.; conceptualization, methodology, and validation: M.-L.T., A.H.M.M., and J.-Z.W.; funding acquisition, supervision, and project administration: J.-Z.W. All authors have read and agreed to the published version of the manuscript.

Funding: The study is partially supported by the Ministry of Science and Technology, Taiwan (MOST108-2911-I-031-502; MOST108-2221-E-031-001-MY2) and the Center for Applied Artificial Intelligence Research, Soochow University, Taiwan (C-01).

Institutional Review Board Statement: Not applicable.

Informed Consent Statement: Not applicable.

Data Availability Statement: Not applicable.

Conflicts of Interest: The authors have no conflicts of interest to declare. The funders had no role in the design of the study; in the collection, analyses, or interpretation of data; in the writing of the manuscript; or in the decision to publish the results.

\section{Appendix A}

The following notations were used for the development of the SSCI models.

\section{Parameters}

A Fixed ordering cost (\$/setup/year).

$\eta \quad$ Proportion of backorders in stock-out time $(0<\eta<1)$ for the partial backorder model.

c Purchasing cost (\$/unit/year).

$P \quad$ PRT cost per unit time.

$\lambda_{0} \quad$ Deterioration rate without PRT investment (unit/year).

$u \quad$ Sensitivity parameter for PRT investment relative to the rate of deterioration (unit).

$h \quad$ Holding cost (\$/unit/year).

$l$ Rate of capital cost (\$/unit/year).

$k \quad$ Purchasing cost that must be prepaid in advance $0<k<1$ (\$/unit/year).

$R \quad$ Number of installments (unit/order/year).

$L \quad$ Supplier's lead time (order/year).

$\mu \quad$ Retailer's revenues when placing an order $0<\mu<1$ (unit/order/year).

$r$ Discount rate (\%/year).

$f \quad$ Backordering cost (\$/unit/year).

$s \quad$ Sales cost of lost goodwill (\$/unit)

Carbon emission parameters

$\delta \quad$ Carbon tax rate $(\$ / \mathrm{kg} /$ year $)$.

$w$ Carbon emissions cap ( $\mathrm{kg} /$ year).

$g \quad$ Carbon emissions from holding warehouse stock ( $\mathrm{kg} /$ year).

$B$ Carbon emissions due from placing orders ( $\mathrm{kg} /$ order/year).

$K \quad$ Carbon emissions due to production (kg/year).

$G \quad$ GRT cost per unit time for emissions reduction.

$\theta \quad$ Fraction of carbon emissions after GRT investment $(0<\theta<1)$.

$m$ Sensitivity parameter for GRT investment relative to carbon emissions rates $(m>0)$. 


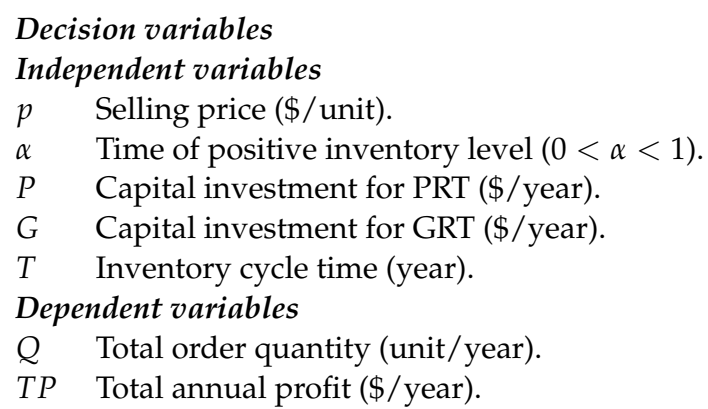

\section{Appendix B}

Proof: Equation (22) implies the following:

$$
\begin{aligned}
& \frac{\partial T P(T, \alpha, P, G, p)}{\partial T}=\frac{A}{T^{2}}-\frac{1}{2} e^{M \zeta} h(a-b p) \alpha^{2}-\frac{1}{2} e^{M \zeta} f(a-b p)(1-\alpha)^{2} \eta- \\
& c e^{M \zeta} l(a-b p)\left(\frac{1}{2} \alpha^{2}(1-\mu)+\frac{\alpha^{2} \mu}{2}\right)-\frac{1}{2} c e^{-P u+M \zeta}(a-b p) \alpha^{2} \lambda_{0} \\
& -\frac{c e^{-P u+M \zeta} k l L(a-b p)(1+R) \alpha^{2} \lambda_{0}}{4 R}-\delta\left(1-\left(1-e^{-G m}\right) \theta\right) \\
& \times\left(-\frac{B}{T^{2}}+\frac{1}{2} e^{M \zeta} g(a-b p) \alpha^{2}+\frac{1}{2} e^{-P u+M \zeta} K(a-b p) \alpha^{2} \lambda_{0}\right) \\
& \frac{\partial^{2} T P(T, \alpha, P, G, p)}{\partial T^{2}}=-\frac{2(A+B \delta)\left(1-\left(1-e^{-G m}\right) \theta\right)}{T^{3}} \\
& \frac{\partial T P(T, \alpha, P, G, p)}{\partial \alpha}=-e^{M \zeta} h(a-b p) T \alpha \\
& +e^{M \zeta}(a-b p) s(1-\eta)+e^{M \zeta} f(a-b p) T(1-\alpha) \eta \\
& +e^{-M \phi}\left(e^{-M r+M \zeta}\left(a p-b p^{2}\right)-e^{-M r+M \zeta}\left(a p-b p^{2}\right) \eta\right) \\
& -c e^{M \zeta} l(a-b p)(M(1-\mu)+T \alpha(1-\mu)+T \alpha \mu) \\
& -c e^{M \zeta}(a-b p)\left(1-\eta+e^{-P u} T \alpha \lambda_{0}\right) \\
& -\frac{c e^{M \zeta} k l L(a-b p)(1+R)\left(1-\eta+e^{-P u} T \alpha \lambda_{0}\right)}{2 R} \\
& \frac{\partial^{2} T P(T, \alpha, P, G, p)}{\partial \alpha^{2}}=-h(a-b p) e^{M \zeta} T-e^{M \zeta} f(a-b p) T \eta \\
& -c l(a-b p) e^{M \zeta}(T(1-\mu)+T \mu)-c e^{-P u+M \zeta}(a-b p) T \lambda_{0} \\
& -\frac{c e^{-P u+M \zeta} k l L(a-b p)(1+R) T \lambda_{0}}{2 R} \\
& -\delta\left(1-\theta\left(1-e^{-G m}\right)\right)\left(e^{M \zeta} g(a-b p) T+e^{-P u+M \zeta} K(a-b p) T \lambda_{0}\right) \\
& \frac{\partial T P(T, \alpha, P, G, p)}{\partial P}= \\
& -1+\frac{1}{2} c e^{-P u+M \zeta}(a-b p) T u \alpha^{2} \lambda_{0}+\frac{c e^{-P u+M \zeta} k l L(a-b p)(1+R) T u \alpha^{2} \lambda_{0}}{4 R} \\
& \frac{\partial T P(T, \alpha, P, G, p)}{\partial G}= \\
& -1+e^{-G m} m \delta \theta\left(\begin{array}{l}
\frac{B}{T}+\frac{1}{2} e^{M \zeta} g(a-b p) T \alpha^{2}+e^{M \zeta} K(a-b p) \\
\times\left(\alpha+(1-\alpha) \eta+\frac{1}{2} e^{-P u} T \alpha^{2} \lambda_{0}\right)
\end{array}\right)
\end{aligned}
$$

$$
\begin{aligned}
& \frac{\partial T P(T, \alpha, P, G, p)}{\partial p}=\frac{1}{2} b e^{M \zeta} h T \alpha^{2}+b e^{M \zeta} S(1-\alpha)(1-\eta)+\frac{1}{2} b e^{M \zeta} f T(1-\alpha)^{2} \eta \\
& +e^{-M \phi}\left(e^{-M r+M \zeta}(a-2 b p) \alpha+e^{-M r+M \zeta}(a-2 b p)(1-\alpha) \eta\right) \\
& +b c e^{M \zeta} l\left(M \alpha(1-\mu)+\frac{1}{2} T \alpha^{2}(1-\mu)+\frac{1}{2} T \alpha^{2} \mu\right) \\
& +b c e^{M \zeta}\left(\alpha+(1-\alpha) \eta+\frac{1}{2} e^{-P u} T \alpha^{2} \lambda_{0}\right) \\
& +\frac{b c e^{M \zeta} k l L(1+R)\left(\alpha+(1-\alpha) \eta+\frac{1}{2} e^{-P u} T \alpha^{2} \lambda_{0}\right)}{2 R} \\
& -\delta\left(1-\left(1-e^{-G m}\right) \theta\right)\left(-\frac{1}{2} b e^{M \zeta} g T \alpha^{2}-b e^{M \zeta} K\left(\alpha+(1-\alpha) \eta+\frac{1}{2} e^{-P u} T \alpha^{2} \lambda_{0}\right)\right)
\end{aligned}
$$




$$
\frac{\partial^{2} T P(T, \alpha, P, G, p)}{\partial p^{2}}=-e^{-M \phi}\left(2 b e^{-M r+M \zeta} \alpha+2 b e^{-M r+M \zeta}(1-\alpha) \eta\right)<0
$$

Then, we prove the concavity of $T P$ with regard to $P$ and $G$ for any positive values of

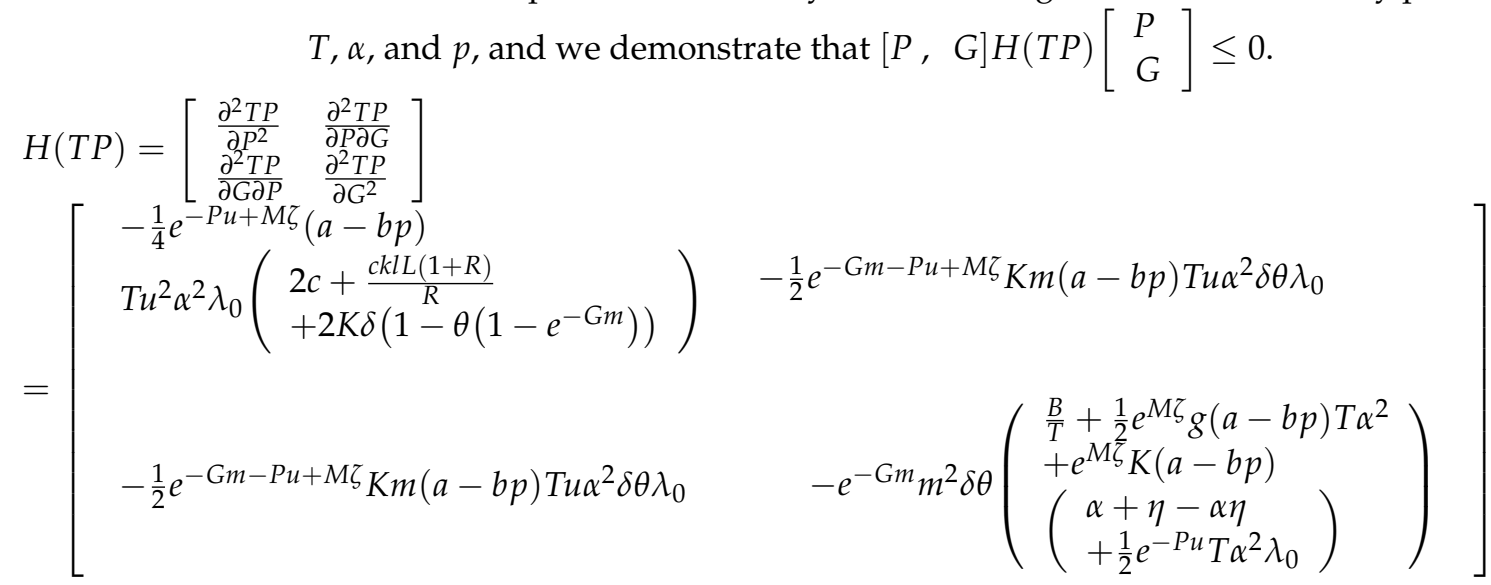

The calculus for concavity proves the following condition:

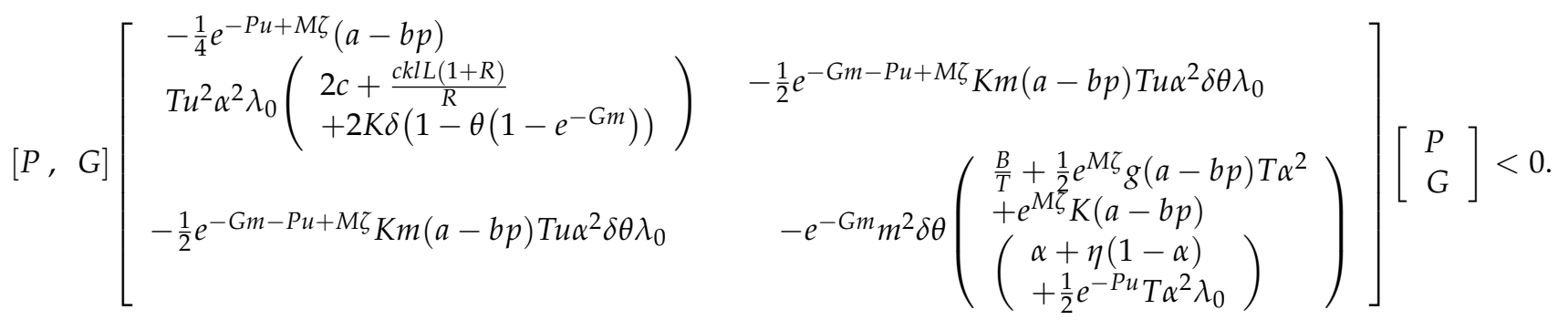

$[P, G]\left[\begin{array}{cc}-\frac{1}{4} e^{-P u+M \zeta}(a-b p) \\ T u^{2} \alpha^{2} \lambda_{0}\left(\begin{array}{c}2 c+\frac{c k l L(1+R)}{R} \\ +2 K \delta\left(1-\theta\left(1-e^{-G m}\right)\right)\end{array}\right) & -\frac{1}{2} e^{-G m-P u+M \zeta} K m(a-b p) T u \alpha^{2} \delta \theta \lambda_{0} \\ -\frac{1}{2} e^{-G m-P u+M \zeta} K m(a-b p) T u \alpha^{2} \delta \theta \lambda_{0} & -e^{-G m} m^{2} \delta \theta\left(\begin{array}{c}\frac{B}{T}+\frac{1}{2} e^{M \zeta} g(a-b p) T \alpha^{2} \\ +e^{M \zeta} K(a-b p) \\ \left(\begin{array}{c}\alpha+\eta(1-\alpha) \\ +\frac{1}{2} e^{-P u} T \alpha^{2} \lambda_{0}\end{array}\right)\end{array}\right)\end{array}\right]\left[\begin{array}{l}P \\ G\end{array}\right]$ $=-\frac{1}{4} e^{-P u+M \zeta}(a-b p) T u^{2} \alpha^{2} \lambda_{0}\left(\begin{array}{l}2 c+\frac{c k l L(1+R)}{R} \\ +2 K \delta\left(1-\theta\left(1-e^{-G m}\right)\right)\end{array}\right) P^{2}$

$-\frac{1}{2} e^{-G m-P u+M \zeta} K m(a-b p) T u \alpha^{2} \delta \theta \lambda_{0} G P-\frac{1}{2} e^{-G m-P u+M \zeta} K m(a-b p) T u \alpha^{2} \delta \theta \lambda_{0} P G-$

$-e^{-G m} m^{2} \delta \theta\left(\begin{array}{c}\frac{B}{T}+\frac{1}{2} e^{M \zeta} g(a-b p) T \alpha^{2} \\ +e^{M \zeta} K(a-b p) \\ \left(\begin{array}{c}\alpha+\eta(1-\alpha) \\ +\frac{1}{2} e^{-P u} T \alpha^{2} \lambda_{0}\end{array}\right)\end{array}\right) G^{2}<0$

where $\left(1-\theta\left(1-e^{-G m}\right)\right)>0,(a-b p)>0$, and $\alpha+\eta(1-\alpha)>0 . \square$

\section{Appendix C}

Proof: This proof is the same as that shown in Appendix B with $\eta=1$.

\section{Appendix D}

Proof: This proof is the same as that shown in Appendix B with $\eta=1$ and $\alpha=1$. 


\section{References}

1. Toptal, A.; Özlü, H.; Konur, D. Joint decisions on inventory replenishment and emission reduction investment under different emission regulations. Int. J. Prod. Res. 2014, 52, 243-269. [CrossRef]

2. Mashud, A.H.M.; Wee, H.M.; Sarkar, B.; Li, Y.H.C. A sustainable inventory system with the advanced payment policy and trade-credit strategy for a two-warehouse inventory system. Kybernetes 2020. [CrossRef]

3. IPCC (Intergovernmental Panel on Climate Change). Climate Change. In The Fourth Assessment Report of the Intergovernmental Panel on Climate Change; Cambridge University Press: Cambridge, UK, 2007.

4. Lou, G.X.; Xia, H.Y.; Zhang, J.Q.; Fan, T.J. Investment Strategy of Emission-Reduction Technology in a Supply Chain. Sustainability 2015, 7, 10684-10708. [CrossRef]

5. Dye, C.-Y.; Yang, C.T. Sustainable trade credit and replenishment decisions with credit-linked demand under carbon emission constraints. Eur. J. Oper. Res. 2015, 244, 187-200. [CrossRef]

6. Mashud, A.H.M.; Wee, H.; Huang, C.-V. Preservation technology investment, trade credit and partial backordering model for a non-instantaneous deteriorating inventory. RAIRO Oper. Res. 2019. [CrossRef]

7. Mashud, A.H.M.; Hasan, R.; Wee, H.M.; Daryanto, Y. Non-instantaneous deteriorating inventory model under the joined effect of trade-credit, preservation technology and advertisement policy. Kybernetes 2019, 49, 1645-1674. [CrossRef]

8. Chen, S.-C.; Teng, J.-T. Inventory and credit decisions for time-varying deteriorating items with up-stream and down-stream trade credit financing by discounted cash flow analysis. Eur. J. Oper. Res. 2015, 243, 566-575. [CrossRef]

9. Johari, M.; Hosseini-Motlagh, S.-M.; Nematollahi, M.; Goh, M.; Ignatius, J. Bi-level credit period coordination for periodic review inventory system with price-credit dependent demand under time value of money. Transp. Res. Part E: Logist. Transp. Rev. 2018, 114, 270-291. [CrossRef]

10. Cheraghalipour, A.; Farsad, S. A bi-objective sustainable supplier selection and order allocation considering quantity discounts under disruption risks: A case study in plastic industry. Comput. Ind. Eng. 2018, 118, 237-250. [CrossRef]

11. Teng, J.-T.; Cárdenas-Barrón, L.E.; Chang, H.-J.; Wu, J.; Hu, Y. Inventory lot-size policies for deteriorating items with expiration dates and advance payments. Appl. Math. Model. 2016, 40, 8605-8616. [CrossRef]

12. Mishra, U.; Wu, J.-Z.; Tsao, Y.-C.; Tseng, M.-L. Sustainable inventory system with controllable non-instantaneous deterioration and environmental emission rates. J. Clean. Prod. 2020, 244, 118807. [CrossRef]

13. Lashgari, M.; Taleizadeh, A.A.; Ahmadi, A. Partial up-stream advanced payment and partial down-stream delayed payment in a three-level supply chain. Ann. Oper. Res. 2015, 238, 329-354. [CrossRef]

14. Hasan, R.; Roy, T.C.; Daryanto, Y.; Wee, H.-M. Optimizing inventory level and technology investment under a carbon tax, cap-and-trade and strict carbon limit regulations. Sustain. Prod. Consum. 2021, 25, 604-621. [CrossRef]

15. Bakker, M.; Riezebos, J.; Teunter, R.H. Review of inventory systems with deterioration since 2001. Eur. J. Oper. Res. 2012, 221, 275-284. [CrossRef]

16. Ghiami, Y.; Beullens, P. The continuous resupply policy for deteriorating items with stock-dependent observable demand in a two-warehouse and two-echelon supply chain. Appl. Math. Model. 2020, 82, 271-292. [CrossRef]

17. Ghosh, A.; Jha, J.; Sarmah, S. Optimal lot-sizing under strict carbon cap policy considering stochastic demand. Appl. Math. Model. 2017, 44, 688-704. [CrossRef]

18. Zhang, Q.; Tsao, Y.-C.; Chen, T.-H. Economic order quantity under advance payment. Appl. Math. Model. 2014, 38, 5910-5921. [CrossRef]

19. Taleizadeh, A.A. An economic order quantity model for deteriorating item in a purchasing system with multiple prepayments. Appl. Math. Model. 2014, 38, 5357-5366. [CrossRef]

20. Zia, N.P.; Taleizadeh, A.A. A lot-sizing model with backordering under hybrid linked-to-order multiple advance payments and delayed payment. Transp. Res. Part E: Logist. Transp. Rev. 2015, 82, 19-37. [CrossRef]

21. Tavakoli, S.; Taleizadeh, A.A. An EOQ model for decaying item with full advanced payment and conditional discount. Ann. Oper. Res. 2017, 259, 415-436. [CrossRef]

22. Shah, N.H.; Jani, M.Y.; Chaudhari, U. Optimal replenishment time for retailer under partial upstream prepayment and partial downstream overdue payment for quadratic demand. Math. Comput. Model. Dyn. Syst. 2017, 24, 1-11. [CrossRef]

23. Taleizadeh, A.A.; Tavakoli, S.; San-José, L.A. A lot sizing model with advance payment and planned backordering. Ann. Oper. Res. 2018, 271, 1001-1022. [CrossRef]

24. Roghanian, E.; Cheraghalipour, A. Addressing a set of meta-heuristics to solve a multi-objective model for closed-loop citrus supply chain considering $\mathrm{CO}_{2}$ emissions. J. Clean. Prod. 2019, 239, 118081. [CrossRef]

25. Taleizadeh, A.A.; Hazarkhani, B.; Moon, I. Joint pricing and inventory decisions with carbon emission considerations, partial backordering and planned discounts. Ann. Oper. Res. 2018, 290, 95-113. [CrossRef]

26. Taleizadeh, A.A.; Soleymanfar, V.R.; Govindan, K. Sustainable economic production quantity models for inventory systems with shortage. J. Clean. Prod. 2018, 174, 1011-1020. [CrossRef]

27. Tiwari, S.; Ahmed, W.; Sarkar, B. Multi-item sustainable green production system under trade-credit and partial backordering. J. Clean. Prod. 2018, 204, 82-95. [CrossRef]

28. Tiwari, S.; Daryanto, Y.; Wee, H.M. Sustainable inventory management with deteriorating and imperfect quality items considering carbon emission. J. Clean. Prod. 2018, 192, 281-292. [CrossRef] 
29. Mashud, A.H.M.; Roy, D.; Daryanto, Y.; Ali, M.H. A Sustainable Inventory Model with Imperfect Products, Deterioration, and Controllable Emissions. Mathematics 2020, 8, 2049. [CrossRef]

30. Kumar, M.G.; Uthayakumar, R. Modelling on vendor-managed inventory policies with equal and unequal shipments under GHG emission-trading scheme. Int. J. Prod. Res. 2018, 57, 3362-3381. [CrossRef]

31. Ebrahimi, S.B. A stochastic multi-objective location-allocation-routing problem for tire supply chain considering sustainability aspects and quantity discounts. J. Clean. Prod. 2018, 198, 704-720. [CrossRef]

32. Wang, J.; Zhou, Z.; Yu, M. Pricing models in a sustainable supply chain with capacity constraint. J. Clean. Prod. 2019, 222, 57-76. [CrossRef]

33. Wang, Q.; Wu, J.; Zhao, N.; Zhu, Q. Inventory control and supply chain management: A green growth perspective. Resour. Conserv. Recycl. 2019, 145, 78-85. [CrossRef]

34. Gharaei, A.; Karimi, M.; Shekarabi, S.A.H. An integrated multi-product, multi-buyer supply chain under penalty, green, and quality control polices and a vendor managed inventory with consignment stock agreement: The outer approximation with equality relaxation and augmented penalty algorithm. Appl. Math. Model. 2019, 69, 223-254. [CrossRef]

35. Kumar, S.; Handa, N.; Singh, S.; Yadav, D. Production inventory model for two-level trade credit financing under the effect of preservation technology and learning in supply chain. Cogent Eng. 2015, 2, 1045221. [CrossRef]

36. Mohanty, D.J.; Kumar, R.S.; Goswami, A. Trade-credit modeling for deteriorating item inventory system with preservation technology under random planning horizon. Sadhana 2018, 43, 45. [CrossRef]

37. Zilberman, D.; Lu, L.; Reardon, T. Innovation-induced food supply chain design. Food Policy 2019, 83, 289-297. [CrossRef]

38. Du, X.; Lu, L.; Reardon, T.; Zilberman, D. Economics of Agricultural Supply Chain Design: A Portfolio Selection Approach. Am. J. Agric. Econ. 2016, 98, 1377-1388. [CrossRef]

39. Lu, L.; Reardon, T.; Zilberman, D. Supply Chain Design and Adoption of Indivisible Technology. Am. J. Agric. Econ. 2016, 98, 1419-1431. [CrossRef]

40. Mashud, A.H.M.; Wee, H.-M.; Huang, C.-V.; Wu, J.-Z. Optimal Replenishment Policy for Deteriorating Products in a Newsboy Problem with Multiple Just-in-Time Deliveries. Mathematics 2020, 8, 1981. [CrossRef]

41. Baek, S.H.; Kim, J.S. Efficient Algorithms for a Large-Scale Supplier Selection and Order Allocation Problem Considering Carbon Emissions and Quantity Discounts. Mathematics 2020, 8, 1659. [CrossRef]

42. Sett, B.K.; Dey, B.K.; Sarkar, B. The Effect of O2O Retail Service Quality in Supply Chain Management. Mathematics 2020, 8, 1743. [CrossRef]

43. Vishkaei, B.M.; Seyyed-Esfahani, M.; Mahdavi, I.; Askari, M. A retailer inventory model when the reliability of inspection system affects the percentage of defective items which are delivered to final customers. J. Ind. Prod. Eng. 2019, 36, 70-80. [CrossRef]

44. Esmaeili, M.; Nasrabadi, M. An inventory model for single-vendor multi-retailer supply chain under inflationary conditions and trade credit. J. Ind. Prod. Eng. 2021, 38, 75-88. [CrossRef]

45. Taghizadeh-Yazdi, M.; Farrokhi, Z.; Mohammadi-Balani, A. An integrated inventory model for multi-echelon supply chains with deteriorating items: A price-dependent demand approach. J. Ind. Prod. Eng. 2020, 37, 87-96. [CrossRef]

46. Mishra, U.; Wu, J.-Z.; Sarkar, B. Optimum sustainable inventory management with backorder and deterioration under controllable carbon emissions. J. Clean. Prod. 2021, 279, 123699. [CrossRef]

47. Giri, B.; Maiti, T. Supply chain model with price- and trade credit-sensitive demand under two-level permissible delay in payments. Int. J. Syst. Sci. 2013, 44, 937-948. [CrossRef]

48. Qin, J.; Bai, X.; Xia, L. Sustainable Trade Credit and Replenishment Policies under the Cap-And-Trade and Carbon Tax Regulations. Sustainability 2015, 7, 16340-16361. [CrossRef]

49. Mishra, U.; Cárdenas-Barrón, L.E.; Tiwari, S.; Shaikh, A.A.; Treviño-Garza, G. An inventory model under price and stock dependent demand for controllable deterioration rate with shortages and preservation technology investment. Ann. Oper. Res. 2017, 254, 165-190. [CrossRef] 